九州大学学術情報リポジトリ

Kyushu University Institutional Repository

\title{
Total synthesis of xanthanolides
}

Matsuo, Kazumasa

Interdisciplinary Graduate School of Engineering Sciences, Kyushu University

Ohtsuki, Keiko

Interdisciplinary Graduate School of Engineering Sciences, Kyushu University

Yoshikawa, Takashi

Interdisciplinary Graduate School of Engineering Sciences, Kyushu University

Shishido, Kozo

Graduate School of Pharmaceutical Sciences, The University of Tokushima

他

ht tp://hdl. hand le. net/2324/26298

出版情報：Tetrahedron. 66（43)，pp.8407-8419，2010-10-23. Elsevier バージョン:

権利関係: (C) 2010 Elsevier Ltd. 


\section{Graphical Abstract}

\section{Total Synthesis of Xanthanolides}

Kazumasa Matsuo, Keiko Ohtsuki, Takashi Yoshikawa, Kozo Shishido, Kaori Yokotani-Tomita, Mitsuru Shindo*<smiles>C[C@H]1C[C@H]2OC(=O)[C@H](C)[C@H]2CC=C1CCO</smiles>

(+)-sundiversifolide

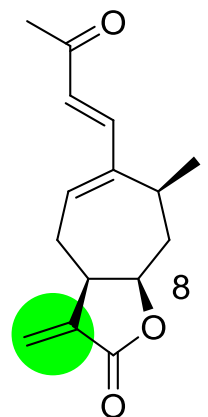

$(+)-8$-epi-xanthatin

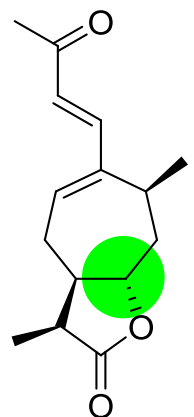

(-)-dihydroxanthatin

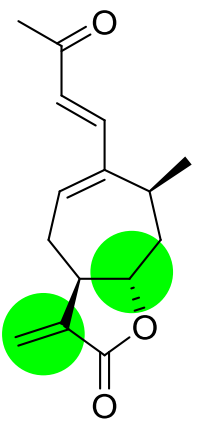

(-)-xanthatin 


\title{
Total Synthesis of Xanthanolides
}

Kazumasa Matsuo, ${ }^{\mathrm{a}}$ Keiko Ohtsuki, ${ }^{\mathrm{a}}$ Takashi Yoshikawa, ${ }^{\mathrm{a}}$ Kozo Shishido, ${ }^{\mathrm{b}}$ Kaori Yokotani-Tomita, ${ }^{\mathrm{c}}$ Mitsuru Shindo d,*

${ }^{a}$ Interdisciplinary Graduate School of Engineering Sciences, Kyushu University, Kasuga-koen, Kasuga 816-8580, Japan

${ }^{b}$ Graduate School of Pharmaceutical Sciences, The University of Tokushima

${ }^{c}$ Graduate School of Life and Environmental Sciences, University of Tsukuba, Tsukuba, Ibaraki 305-8572, Japan

${ }^{d}$ Institute for Materials Chemistry and Engineering, Kyushu University, Kasuga-koen, Kasuga 816-8580, Japan

*Corresponding author. Fax: +81 92583 7875; e-mail: shindo@cm.kyushu-u.ac.jp

\begin{abstract}
The total synthesis and determination of the absolute configuration of (+)- and (-)-sundiversifolide have been achieved via intramolecular acylation and Wittig lactonization as the key steps. The xanthanolide sesquiterpene lactones, 8-epi-xanthatin (1), dihydroxanthatin (2), and xanthatin (3) were also prepared, starting from a common intermediate derived from the synthesis of sundiversifolide.
\end{abstract}

Keywords: Xanthanolides, Natural products, Sesquiterpene lactones, Total synthesis

\section{Introduction}

The xanthanolide sesquiterpene lactones are a class of natural products isolated from the plants of the genus Xanthium (family Compositae). They have a bicyclic 5,7-fused ring system, and are known to exhibit allelopathic, ${ }^{1}$ antitumor, ${ }^{2}$ antimalarial, ${ }^{3}$ and antimicrobial activity. ${ }^{4}$ Accordingly, their intriguing biological profile has attracted the interest of medicinal chemists and biochemists as well as organic chemists. An efficient synthesis of these sesquiterpenes therefore would be extremely useful in order to identify biological targets and develop related drugs. Xanthatin (3), isolated from Xanthium strumarium ${ }^{5}$ and other Xanthium families, has shown potent antibacterial activity against methicillin-sensitive and methicillin-resistant Staphylococcus aureus. ${ }^{6}$ 8-epi-Xanthatin (1), which is found in the extracts of the aerial parts of various species in the genus Xanthium, ${ }^{7}$ has also been 
reported to exhibit antitumor activity ${ }^{2 \mathrm{a}}$ and in vitro inhibitory activity on farnesyltransferase, ${ }^{2 \mathrm{~d}}$ insect development, ${ }^{7 \mathrm{~b}}$ and auxin-induced growth of sunflower hypocotyls. ${ }^{1 \mathrm{~b}, 1 \mathrm{c}}$ In spite of these attractive bioactivities, only a few synthetic studies of the xanthanolides and their related natural products have been reported. ${ }^{8,9}$ Recently, we have achieved an efficient total synthesis of a dinorxanthanolide, (+)-sundiversifolide (4), ${ }^{9 \mathrm{~b}}$ which was isolated from the exudate of germinating sunflowers (Helianthus annuus L.) as an allelopathic compound, ${ }^{1 \text { a }}$ via a novel construction of the seven-membered carbocycle by an intramolecular acylation and a one-pot Wittig-lactonization as the key steps. This synthesis afforded useful intermediates having a bicyclic 5,7-fused ring system for the synthesis of the xanthanolides. Herein, we report the total synthesis of (+)-8-epi-xanthatin (1), (-)-dihydroxanthatin (2), and (-)-xanthatin (3) starting from the common key intermediate $\mathbf{5}$ as well as full details of the total synthesis of (+)-sundiversifolide.

\section{Figure 1.}

\section{Results and discussion}

\subsection{Synthesis of sundiversifolide and the key intermediate for the xanthanolides}

Our synthetic strategy for the key intermediate $\mathbf{5}$ is illustrated in Scheme 1 . The $\gamma$-lactone moiety would be formed by acylation-olefination of the hydroxyketone $\mathbf{6}$, followed by hydrogenation. The vinyl side chain on C-1 would then be introduced by alkylation of the ketone 7 . The seven-membered ring construction is much more challenging than the six-membered ring, due to the entropically unfavorable ring size and/or non-bonded interactions in the transition state. To overcome these issues, we envisioned an intramolecular acylation of a carbanion on the $\gamma$-lactone 9 leading to the 8-oxabicyclo[3.2.1] octane skeleton $\mathbf{8}$ via a six-membered ring formation. Since the fused oxabicycle 8 is a hemiacetal, the hydroxycycloheptanone 7 would be easily provided. The relevant strategy has been reported by Molander and coworkers utilizing $\mathrm{SmI}_{2} \cdot{ }^{10}$ The asymmetric centers on 9 would be obtained by a diastereoselective alkylation using the chiral oxazolidinone 11, followed by stereocontrolled dihydroxylation of the resulting $\mathbf{1 0}$.

\section{Scheme 1.}

The alkylating reagent $\mathbf{1 2}$ was prepared from 3-butyn-1-ol in five steps via protection, hydroxymethylation, hydroalumination-protonation, and mesylation-iodination. The diastereoselective alkylation of Evans' oxazolidinone $\mathbf{1 1}$ with 12 provided $\mathbf{1 3}$ in good yield with excellent stereoselectivity. ${ }^{11}$ The stereocontrolled dihydroxylation of $\mathbf{1 3}$ with AD-mix- $\beta^{\circledR 12}$ was accompanied by spontaneous lactonization of the intermediate diol to afford the lactone $\mathbf{1 4}$ as a single isomer. Protection of the secondary alcohol with $\mathrm{MOMCl}$ and deprotection of the TBDPS 
ether with TBAF in $\mathrm{THF}^{13}$ followed by mesylation-iodination, furnished the iodolactone $\mathbf{1 7}$ in good yield (Scheme 2).

\section{Scheme 2.}

The pivotal intramolecular acylation forming the seven-membered ring was first attempted with $\mathrm{SmI}_{2}$ under various conditions and resulted in no reaction. Instead, lithiation of the iodide $\mathbf{1 7}$ using $t$-BuLi successfully provided the seven-membered ring in excellent yield. ${ }^{13}$ The NMR spectra showed that the product is in equilibrium between the hemiacetal 18 and the cycloheptanone 19 in $\mathrm{CDCl}_{3}$. Treatment of the product with TBDPSCl and imidazole gave the trisubstituted cycloheptanone $\mathbf{2 0}$ in good yield (Scheme 3).

\section{Scheme 3.}

With the seven-membered skeleton in hand, we next attempted the introduction of the vinyl unit along with the formation of the C1-C5 endocyclic-olefin (Scheme 4). The vinyl Grignard reagent added stereoselectively to the ketone to give $\mathbf{2 1}$ in good yield as a single isomer. According to the conformational analysis of $\mathbf{2 0},{ }^{14}$ the nucleophile would attack the $\alpha$-face as an equatorial attack (Figure 2). Attempts to dehydrate with thionyl chloride gave the chlorinated compound 22 via an $\mathrm{S}_{\mathrm{N}} 2$ ' reaction, and the Burgess reagent resulted in formation of the oxabicyclic compound 23.

\section{Scheme 4.}

Figure 2.

We then tried the enol triflation of the ketone $\mathbf{2 0}$ which gave only recovered starting material, but the Shapiro reaction of the corresponding $p$-toluenesulfonyl hydrazone $\mathbf{2 4}$ afforded the alkenyl iodide $\mathbf{2 5}$ in $77 \%$ yield after trapping of the alkenyllithium with iodine. Stille coupling with $\mathbf{2 5}$ and tributylvinyltin provided the vinylcycloheptene 26. Since we first intended to achieve the synthesis of sundiversifolide, the vinyl compound $\mathbf{2 6}$ was subjected to hydroboration with thexylborane to provide primary alcohol 27 after oxidative treatment. After protection of the hydroxyl group, deprotection of the MOM ether was attempted by using various kinds of acid, but resulted in low yield, and the oxabicyclic compound $\mathbf{3 0}$ was again obtained. The tertiary carbocation at C-1 would be easily generated to form this product. 


\section{Scheme 5.}

In place of the MOM ether, a TBS ether was selected as the protecting group of the hydroxyl group at C-7. Treatment of $\mathbf{1 4}$ with $\mathrm{TBSCl}$ gave 31, the primary TBDPS ether of which should be selectively deprotected. Although the usual protocol (TBAF, AcOH in THF) ${ }^{15}$ gave mainly the diol 37, in the presence of $\mathrm{CH}_{2} \mathrm{Cl}_{2}$ as a co-solvent, ${ }^{16}$ the desired partially deprotected alcohol 32 was obtained in good yield. However, on a scale larger than $10 \mathrm{~g}$ of substrate, the yield of $\mathbf{3 2}$ decreased to $60 \%$ and more of the diol $\mathbf{3 7}$ was generated. The alcohol $\mathbf{3 2}$ was converted into the iodide $\mathbf{3 3}$ quantitatively. The diol $\mathbf{3 7}$ also can be transformed into the iodide $\mathbf{3 3}$ via selective iodination followed by protection of the secondary alcohol with TBSOTf. The iodide $\mathbf{3 3}$ was treated with $t$-BuLi to afford the hemiacetal $\mathbf{3 4}$ and the cycloheptanone $\mathbf{3 5}$ in excellent yield. Although $\mathrm{MOMCl}$ reacted with the hydroxyl groups on both $\mathbf{3 4}$ and $\mathbf{3 5}$, TBDPSCl protected only the secondary alcohol of $\mathbf{3 5}$ to afford $\mathbf{3 6}$ in good yield (Scheme 6).

\section{Scheme 6.}

The Shapiro reaction was carried out on the corresponding hydrazone $\mathbf{3 7}$ to give the doubly iodinated compound $\mathbf{3 8}$ in low yield after treatment with iodine.

\section{Scheme 7.}

Hence, we then attempted the nucleophilic vinylation of $\mathbf{3 6}$ with a Grignard reagent as in the previous case. ${ }^{17}$ Vinylmagnesium bromide added to the ketone to afford the adduct $\mathbf{3 9}$ in excellent yield as a single isomer. Since dehydration of the tertiary alcohol of $\mathbf{3 9}$ to afford the endocyclic-olefin was unsuccessful at this stage as shown in Scheme 8, we decided to assemble the lactone first. Selective deprotection of the TBS group of $\mathbf{3 9}$, TPAP oxidation of $\mathbf{4 0}$, and removal of the TBDPS group of $\mathbf{4 1}$ provided the hydroxy hemiacetal $\mathbf{4 2}$ in nearly quantitative yield. We next tried to construct the lactone moiety from $\mathbf{4 2}$, which is equivalent to an $\alpha$-hydroxyketone. In order to carry out the intramolecular Horner-Emmons reaction, condensation with the carboxylic acid of the phosphonate $\left((\mathrm{EtO})_{2} \mathrm{P}(\mathrm{O}) \mathrm{CH}\left(\mathrm{CH}_{3}\right) \mathrm{CO}_{2} \mathrm{H}\right)$ and $\mathbf{4 2}$ gave a 1:1 mixture of $\mathbf{4 3}$ and $\mathbf{4 4}$. On the contrary, reaction of 42 with the Wittig reagent $\left(\mathrm{Ph}_{3} \mathrm{P}=\mathrm{C}\left(\mathrm{CH}_{3}\right) \mathrm{CO}_{2} \mathrm{C}_{2} \mathrm{H}_{5}\right)$ under reflux in xylene for 9 hours directly provided the butenolide $\mathbf{4 6}$ in $91 \%$ yield, the structure of which was unambiguously assigned by X-ray diffraction study. In contrast to Garner's report on the Wittig reaction of $\alpha$-hydroxy ketones giving $E$-olefins, ${ }^{18}$ this reaction was exclusively $Z$-selective. The mechanism of this direct lactonization could be postulated as transesterification giving the intermediate $\mathbf{4 5}$, followed by intramolecular olefination, because the ketone in $\mathbf{4 2}$ was masked by hemiacetalization. 
The reaction using the Wittig reagents with the trifluoroethyl ester $\left(\mathrm{R}=\mathrm{CH}_{2} \mathrm{CF}_{3}\right)$ and the phenyl ester $(\mathrm{R}=\mathrm{Ph}$ ), which have better leaving groups, was completed in only 4 hours ( $92 \%$ yield) and 2.5 hours (74\% yield), also suggesting that the intramolecular olefination had occurred (Scheme 8).

With the carbon skeleton in hand, we then investigated the less substituted endocyclic alkene formation. Dehydration using $\mathrm{MsCl} / \mathrm{Et}_{3} \mathrm{~N}$ gave the $\mathrm{S}_{\mathrm{N}} 2$ ' products 47 and not the desired compound.

\section{Scheme 8.}

Since the double bond on the allylic alcohol had to be protected prior to dehydration, $\mathbf{4 6}$ was treated with mCPBA to give the epoxide $\mathbf{4 8}$, which was subjected to hydrogenation with the nickel boride reagent derived from $\mathrm{NiCl}_{2}$ and $\mathrm{NaBH}_{4}{ }^{19}$ to afford a separable mixture of 49 (81\%) and its C11-epimer (14\%). After numerous attempts, the best results for a kinetically controlled dehydration of $\mathbf{4 9}$ were obtained using a protocol involving slow addition of a solution of freshly distilled $\mathrm{SOCl}_{2}$ (2 equiv.) and pyridine (4 equiv.) in $\mathrm{CH}_{2} \mathrm{Cl}_{2}$ at $-20^{\circ} \mathrm{C}$. Under these conditions, the desired endocyclic alkene $\mathbf{5 0}$ was successfully obtained in yields ranging of $68-87 \%$. Finally, the epoxide in $\mathbf{5 0}$ was regioselectively reduced with $\mathrm{NaBH}_{3} \mathrm{CN}$ in the presence of $\mathrm{ZnI}_{2}{ }^{20}$ to provide sundiversifolide (4) in $85 \%$ yield. The synthetic $4\left\{[\alpha]^{22}{ }_{\mathrm{D}}=+33.0\left(\mathrm{c} 0.44, \mathrm{CHCl}_{3}\right)\right\}$ was found to be identical to the natural 4 according to spectroscopic properties $\left({ }^{1} \mathrm{H}\right.$ and ${ }^{13} \mathrm{C}$ NMR, IR, and MS) (Scheme 9). Since the optical rotation data of the natural product has not been reported due to a limited amount of the natural product, the enantiomer ent-1 $\left\{[\alpha]^{22}=-33.7\left(\mathrm{c} 0.46, \mathrm{CHCl}_{3}\right)\right\}$ was synthesized in a similar manner, using the chiral oxazolidinone derived from $L$-Phe in the asymmetric alkylation and $\mathrm{AD}-\mathrm{mix}-\alpha^{\circledR}$ in the asymmetric dihydroxylation, which also gave a single isomer. HPLC analysis using chiral column (Daicel Chiralpak IA, detector: UV $207 \mathrm{~nm}$, hexane/isopropanol 93:7, flow = $1.0 \mathrm{ml} / \mathrm{min}$; (-)-sundiversifolide $t_{\mathrm{r}}=31 \mathrm{~min}$; (+)-sundiversifolide $t_{\mathrm{r}}=38 \mathrm{~min}, 30{ }^{\circ} \mathrm{C}$ ) indicated that the natural $\mathbf{4}$ is identical with the synthetic (+)-4 (Figure 3 ). This study therefore determined that the absolute configuration of the naturally occurring sundiversifolide isolated from the sunflower is that shown in $\mathbf{1}$.

\section{Scheme 9.}

\section{Figure 3.}

\subsection{Synthesis of (+)-8-epi-xanthatin (1)}

The key intermediate $\mathbf{5}$ for construction of xanthanolide has a cis-fused cycloheptene- $\gamma$-butyrolactone skeleton bearing a vinyl substituent, which has been converted into the 
butenone moiety via cross metathesis. ${ }^{8}$ Attempts to reduce the epoxide in $\mathbf{5 0}$ to an alkene using $\mathrm{SmI}_{2}{ }^{21}$ or $\mathrm{P}_{2} \mathrm{I}_{4}{ }^{22}$ resulted in a complex mixture, but $\mathrm{KSeCN}$ successfully reduced the epoxide to give 5 in good yield (Scheme 10). ${ }^{23}$ With the key intermediate in hand, we tried to convert 5 to xanthanolides. In order to prepare 8-epi-xanthatin (1) from 5, conversion of the $\alpha$-methyl group on the $\gamma$-butyrolactone into an exo-methylene was examined. According to Ando's protocol, ${ }^{24}$ bromination at C-11 was employed with $\mathrm{LDA} / \mathrm{CBr}_{4}$ to give a 1:1.4 diastereomeric mixture of $\mathbf{5 1}$ and 52, the stereochemistry of which was determined by NOE experiments as shown in Scheme 10. After separation of these diastereomers, each isomer was subjected to dehydrobromination with base. The $\alpha$-bromo isomer $\mathbf{5 1}$ was easily converted into the desired exo-olefin $\mathbf{5 3}$ by using TBAF in THF. The $\beta$-bromo isomer 52, on the other hand, after being treated with various bases (TBAF, KHMDS, $\mathrm{DBU}$, or Triton B) only gave the conjugated endo-olefin 55, probably due to the anti-periplanar relationship between the bromide and the $\beta$-proton on C-11. Thus, for isomerization of $\mathbf{5 2}$ to $\mathbf{5 1}$, formation of the enolate of $\mathbf{5 2}$ via lithium-halogen exchange, followed by bromination, was attempted using $n$-, sec- or tert-butyllithium, but the desired bromo lactone $\mathbf{5 1}$ was not obtained. Unexpectedly, LDA worked well to generate the enolate $\mathbf{5 6}$ via lithium-halogen exchange, affording a 1:1.4 1:2.5 mixture of $\mathbf{5 1}$ and $\mathbf{5 2}$ after bromination by $\mathrm{CBr}_{4}$. Finally, $\mathbf{5 3}$ was subjected to cross metathesis ${ }^{8}$ using the 2 nd generation Hoveyda-Grubbs catalyst $(\mathbf{5 4})^{25}$ to give 8 -epi-xanthatin (1) in good yield. The spectra of the synthetic $\mathbf{1}$ were identical with those of the natural compound. ${ }^{8 \mathrm{a}}$

\section{Scheme 10.}

\subsection{Synthesis of (-)-dihydroxanthatin (2)}

In order to synthesize dihydroxanthatin (2) from the intermediate 5, a stereochemical inversion at C-8 was necessary. As we reported in the synthesis of diversifolide, ${ }^{9 \mathrm{~d}}$ the lactone moiety was opened by diethylamine and aluminum trichloride to give the hydroxy amide $\mathbf{5 7}$ quantitatively. Since the inversion at C-8 by the Mitsunobu reaction was unsuccessful, probably due to steric reasons, ${ }^{26}$ the oxidation-reduction protocol was examined. TPAP oxidation of the secondary alcohol at C-8, followed by thermodynamically controlled reduction with $\mathrm{SmI}_{2},{ }^{27}$ provided a 4:1 mixture of the desired trans-isomer 59 and the cis-isomer 57, quantitatively. After separation of these isomers, the trans-isomer $\mathbf{5 9}$ was cyclized by acid to furnish the trans-fused lactone $\mathbf{6 0}$, which was subjected to cross metathesis with methyl vinyl ketone as described previously to yield (-)-dihydroxanthatin (2). All the spectra were identical with those of the reported compound. ${ }^{8 c}$

\section{Scheme 11.}




\subsection{Synthesis of (-)-xanthatin (3)}

Xanthatin (3) could be synthesized by "dehydrogenation" of the methyl moiety on dihydroxanthatin (2). According to the procedure described above, the precursor 60 was deprotonated by LDA, followed by bromination with $\mathrm{CBr}_{4}$, to give selectively the brominated compound $\mathbf{6 1}$ with the undesired stereochemistry. ${ }^{28}$ The elimination reaction with base (TBAF, KHMDS) resulted in the formation of the endo-olefin 62, as was seen with 52 (Scheme 10). LDA induced lithiation to give the lithium enolate. Since the trans-fused lactone would have a planar structure, bromination would occur from the $\beta$-face of the enolate rather than the $\alpha$-face to avoid steric hindrance with $\mathrm{H}-7$. We then decided to carry out the stereochemical inversion of C-8 in $\mathbf{5 3}$, since it already had the exo-methylene on the lactone. According to the stereochemical inversion procedure described above, the lactone was opened to give the hydroxy amide $\mathbf{6 3}$, which was oxidized by TPAP to afford the ketone 64. This compound was treated with $\mathrm{SmI}_{2}$ in the same way, but gave 66, resulting from reduction of the enoate as well as the ketone. After screening several reducing reagents, we found that DIBAL reduced only the ketone to give a 1:1.2 ratio of the epimers $(\mathbf{6 5 : 6 3})$. After lactonization with acid, cross metathesis was employed to provide (-)-xanthatin (3) (Scheme 12). The spectra of the synthetic 3 were identical with those of the reports. ${ }^{29}$

\section{Scheme 12.}

\section{Conclusion}

We have achieved the total synthesis of 8-epi-xanthatin (1), dihydroxanthatin (2), and xanthatin (3) starting from a common intermediate, prepared according to our original method, including an intramolecular acylation and a one-pot Wittig-lactonization, used in the synthesis of sundiversifolide. Since these xanthanolides have shown promising bioactivity, this work would be useful for the preparation of these compounds and the development of novel bioactive compounds derived from the natural products.

\section{Experimental}

\subsection{General Procedures}

${ }^{1} \mathrm{H}-\mathrm{NMR}$ and ${ }^{13} \mathrm{C}$-NMR spectra were measured in a $\mathrm{CDCl}_{3}$ solution using JEOL JNM AL-400, $\left({ }^{1} \mathrm{H}-\mathrm{NMR}\right.$ at $400 \mathrm{MHz},{ }^{13} \mathrm{C}-\mathrm{NMR}$ at $\left.100 \mathrm{MHz}\right)$ and a JNM ECA-600 spectrometer $\left({ }^{1} \mathrm{H}\right.$ NMR at 600 $\mathrm{MHz},{ }^{13} \mathrm{C}-\mathrm{NMR}$ at $150 \mathrm{MHz}$ ) as the reference standards $\left({ }^{1} \mathrm{H}\right.$ NMR at $0.00 \mathrm{ppm}$ (TMS), ${ }^{13} \mathrm{C}-\mathrm{NMR}$ at 
$\left.77.0 \mathrm{ppm}\left(\mathrm{CDCl}_{3}\right)\right)$ unless otherwise noted. Chemical shifts are reported in ppm. Peak multiplicities used the following abbreviation: s, singlet; d, doublet; t, triplet; q, quartet; m, multiplet; br, broad. IR spectra were recorded on JASCO FT/IR-410 and Shimazu FT/IR-8300 spectrometers. Mass spectra and high resolution mass spectra were obtained on JMS-K9, JMS-AMSUN200/300, JMS-SX102A, JMS-DX303, and Waters LCT Premier mass spectrometers. Elemental analyses were performed with a Yanaco MT-3, MT-5, MT-6 CHN-Corde. Melting points were measured with a Yanaco MP-500D apparatus and a Seki Technotron Corp. Opti Melt MPA 100 apparatus and are uncorrected. Optical rotations were recorded on JASCO P-1010 and HORIBA SEPA-200. Analytical TLC was performed on precoated plates $\left(0.25 \mathrm{~mm}\right.$, silica gel Merck $\left.60 \mathrm{~F}_{254}\right)$. Column chromatography was performed on silica gel (Kanto Chemical Co., Inc.). Preparative HPLC was performed on Kanto Mightysil Si60 and Merck LiChrosorb Si60, and performed with a gradient solvent system of hexane and ethyl acetate and a UV detector at $254 \mathrm{~nm}$. All reactions were performed under argon or nitrogen atmosphere unless otherwise noted, and dichloromethane $\left(\mathrm{CH}_{2} \mathrm{Cl}_{2}\right)$, diethyl ether $\left(\mathrm{Et}_{2} \mathrm{O}\right)$ and tetrahydrofuran (THF) were purchased from Kanto Chemical Co., Inc., and the other solvents were distilled. Unless otherwise noted, reagents were obtained from chemical sources and used without further purification.

\subsection{Synthesis of sundiversifolide (4)}

4.2.1. (E)-5-(tert-Butyldiphenylsiloxy)-1-iodo-2-pentene $\quad$ 12. To a solution of 5-(tert-butyldiphenylsiloxy)pent-2-en-1-ol $(5.00 \mathrm{~g}, 14.7 \mathrm{mmol})^{30}$ in $\mathrm{CH}_{2} \mathrm{Cl}_{2}(150 \mathrm{~mL})$ at $0{ }^{\circ} \mathrm{C}$ were added $\mathrm{Et}_{3} \mathrm{~N}(5.1 \mathrm{~mL}, 36.7 \mathrm{mmol})$ and $\mathrm{MsCl}(2.3 \mathrm{~mL}, 29.4 \mathrm{mmol})$. The mixture was stirred for $0.5 \mathrm{~h}$ at room temperature, and then cooled to $0{ }^{\circ} \mathrm{C}$. After addition of $\mathrm{H}_{2} \mathrm{O}$, the resulting mixture was extracted with $\mathrm{CH}_{2} \mathrm{Cl}_{2}$, washed with $5 \% \mathrm{HCl}$, saturated aqueous $\mathrm{NaHCO}_{3}$, and brine, and dried over $\mathrm{MgSO}_{4}$. The crude product was dissolved in acetone $(150 \mathrm{~mL})$, and $\mathrm{NaI}(6.60 \mathrm{~g}, 44.0 \mathrm{mmol})$ was added. The resulting suspension was stirred for $0.5 \mathrm{~h}$ at room temperature, and the solvent was removed in vacuo. After addition of $\mathrm{H}_{2} \mathrm{O}$, the mixture was extracted with $\mathrm{CH}_{2} \mathrm{Cl}_{2}$, washed with saturated aqueous $\mathrm{Na}_{2} \mathrm{~S}_{2} \mathrm{O}_{4}$ and brine, and dried over $\mathrm{Na}_{2} \mathrm{SO}_{4}$. After the mixture was evaporated, the residue was purified by silica gel column chromatography (10\% EtOAc-hexane) to give $\mathbf{1 2}$ as a yellow oil (6.53 g, 99\%). ${ }^{1} \mathrm{H}-\mathrm{NMR}\left(400 \mathrm{MHz}, \mathrm{CDCl}_{3}\right) \delta: 1.06(\mathrm{~s}, 9 \mathrm{H}), 2.28(\mathrm{dt}, J=6.6,6.6 \mathrm{~Hz}, 2 \mathrm{H})$, $3.70(\mathrm{t}, J=6.6 \mathrm{~Hz}, 2 \mathrm{H}), 3.86(\mathrm{~d}, J=7.4 \mathrm{~Hz}, 2 \mathrm{H}), 5.72(\mathrm{dt}, J=6.6,15.2 \mathrm{~Hz}, 1 \mathrm{H}), 5.78(\mathrm{dt}, J=7.4$, $15.2 \mathrm{~Hz}, 1 \mathrm{H}), 7.47(\mathrm{~m}, 6 \mathrm{H}), 7.70(\mathrm{~m}, 4 \mathrm{H}) ;{ }^{13} \mathrm{C}-\mathrm{NMR}\left(100 \mathrm{MHz}, \mathrm{CDCl}_{3}\right) \delta: 6.4(\mathrm{t}), 19.3(\mathrm{~s}), 26.9$ (q), $35.4(\mathrm{t}), 63.1(\mathrm{t}), 127.5$ (d), 129.5 (d), 129.7 (d), 131.5 (d), 133.7 (s), 135.5 (d). IR (KBr, neat): 3070, 3048, 2955, 2930, 2857, 1471, $1427 \mathrm{~cm}^{-1}$. MS (FAB) m/z: $473\left(\mathrm{M}^{+}+\mathrm{Na}\right), 135$ (100\%); HRMS (FAB) Calcd for $\mathrm{C}_{21} \mathrm{H}_{27} \mathrm{IOSiNa}\left(\mathrm{M}^{+}+\mathrm{Na}\right)$ 473.0774, Found: 473.0784.

4.2.2. (4R,2 'S)-4-Benzyl-3-[7'-(tert-butyldiphenylsiloxy)-2'-methylhept-4'-enoyl]oxazolidin-2-one 
13. To a solution of diisopropylamine $(1.08 \mathrm{~mL}, 7.73 \mathrm{mmol})$ in THF $(21 \mathrm{~mL})$ at $-78{ }^{\circ} \mathrm{C}$ was added BuLi in pentane $(1.55 \mathrm{M}, 4.9 \mathrm{~mL}, 7.73 \mathrm{mmol})$. The mixture was stirred for $20 \mathrm{~min}$ at $-78^{\circ} \mathrm{C}$, and a solution of $11(1.50 \mathrm{~g}, 6.44 \mathrm{mmol})$ in THF $(10 \mathrm{~mL})$ was added. After the reaction stirred for $1 \mathrm{~h}$ at $-78{ }^{\circ} \mathrm{C}$, a solution of $6(4.35 \mathrm{~g}, 9.66 \mathrm{mmol})$ in THF $(10 \mathrm{~mL})$ was added to the mixture, which was stirred for $6 \mathrm{~h}$ at $-40^{\circ} \mathrm{C}$. After addition of saturated aqueous $\mathrm{NH}_{4} \mathrm{Cl}(3 \mathrm{~mL})$, the resulting mixture was extracted with EtOAc. The combined organic layers were washed with brine $(10 \mathrm{~mL})$, and dried over $\mathrm{MgSO}_{4}$. After the mixture was evaporated, the residue was purified by silica gel column chromatography (30\% EtOAc-hexane) to give $\mathbf{1 3}$ as a colorless oil (3.29 g, 92\%, >99\%d.e.). $[\alpha]_{\mathrm{D}}{ }^{26.4}$ -20.1 (c 1.07, $\left.\mathrm{CHCl}_{3}\right)$, enantiomer; $[\alpha]_{\mathrm{D}}{ }^{20}+20.37\left(c\right.$ 1.08, $\left.\mathrm{CHCl}_{3}\right) .{ }^{1} \mathrm{H}-\mathrm{NMR}\left(400 \mathrm{MHz}, \mathrm{CDCl}_{3}\right) \delta$ : $1.05(\mathrm{~s}, 9 \mathrm{H}), 1.17(\mathrm{~d}, J=6.8 \mathrm{~Hz}, 3 \mathrm{H}), 2.18(\mathrm{ddd}, J=7.2,7.2,12.8 \mathrm{~Hz}, 1 \mathrm{H}), 2.28(\mathrm{dt}, J=6.4,6.4 \mathrm{~Hz}$, 2H), 2.48 (ddd, $J=6.4,6.4,12.8 \mathrm{~Hz}, 1 \mathrm{H}), 2.65$ (dd, $J=10.4,12.8 \mathrm{~Hz}, 1 \mathrm{H}), 3.26$ (dd, $J=2.8,12.8$ $\mathrm{Hz}, 1 \mathrm{H}), 3.69$ (t, $J=7.2 \mathrm{~Hz}, 2 \mathrm{H}), 3.81(\mathrm{tq}, J=6.8,6.8 \mathrm{~Hz}, 1 \mathrm{H}), 4.13(\mathrm{dd}, J=3.2,7.6,10.4 \mathrm{~Hz}, 1 \mathrm{H})$, $5.47(\mathrm{dt}, J=6.4,14.8 \mathrm{~Hz}, 1 \mathrm{H}), 5.54(\mathrm{ddd}, J=7.2,6.4,14.8 \mathrm{~Hz}, 1 \mathrm{H}), 7.20-7.40(\mathrm{~m}, 11 \mathrm{H}), 7.64-7.70$ $(\mathrm{m}, 4 \mathrm{H}) .{ }^{13} \mathrm{C}-\mathrm{NMR}\left(100 \mathrm{MHz}, \mathrm{CDCl}_{3}\right) \delta: 16.4(\mathrm{q}), 19.2(\mathrm{~s}), 26.9(\mathrm{q}), 36.6(\mathrm{t}), 36.9(\mathrm{t}), 37.6(\mathrm{~d}), 38.1$ (t), $55.3(\mathrm{~d}), 63.8$ (t), 66.0 (t), 127.2 (d), 127.5 (d), 127.6 (d), 128.8 (d), 129.3 (d), 129.4 (d), 133.9 (s), 135.4 (s), 135.5 (d), 152.9 (s), 176.5 (s). IR (KBr, neat): 2931, 2858, 1781, $1698 \mathrm{~cm}^{-1}$. MS (FAB) m/z: $578\left(\mathrm{M}^{+}+\mathrm{Na}\right), 135(100 \%)$. HRMS (FAB) Calcd for $\mathrm{C}_{13} \mathrm{H}_{43} \mathrm{NO}_{4} \mathrm{SiNa}\left(\mathrm{M}^{+}+\mathrm{Na}\right)$ 556.2883, Found: 556.2888.

4.2.3. (3S,5R, I 'R)-5-[3'(tert-Butyldiphenylsiloxy)-1'-hydroxypropyl-3-methyldihydrofuran-2-one 14. To a solution of $\mathrm{AD}$-mix $\beta^{\circledR}(16.33 \mathrm{~g})$ in $50 \% t \mathrm{BuOH} / \mathrm{H}_{2} \mathrm{O}(30 \mathrm{~mL})$ was added $\mathrm{MeSO}_{2} \mathrm{NH}_{2}(1.00$ $\mathrm{g}, 10.4 \mathrm{mmol}$ ), and the mixture was stirred for $0.5 \mathrm{~h}$ at room temperature. The resulting mixture was cooled to $0{ }^{\circ} \mathrm{C}$, and a solution of $\mathbf{1 3}(2.33 \mathrm{~g}, 4.17 \mathrm{mmol})$ in $50 \% \mathrm{t}-\mathrm{BuOH} / \mathrm{H}_{2} \mathrm{O}(30 \mathrm{~mL})$ was added. The mixture was stirred for $10 \mathrm{~h}$ at $0{ }^{\circ} \mathrm{C}$, and $\mathrm{Na}_{2} \mathrm{SO}_{3}(3.15 \mathrm{~g}, 25.06 \mathrm{mmol})$ was added. The resulting mixture was stirred for $0.5 \mathrm{~h}$ at room temperature, extracted with $\mathrm{CHCl}_{3}(100 \mathrm{~mL})$, and the combined organic layer was washed with sat. $\mathrm{NaHCO}_{3}$ aq $(50 \mathrm{~mL})$, brine $(50 \mathrm{~mL})$, and dried over $\mathrm{MgSO}_{4}$. After the mixture was evaporated, the residue was purified by silica gel column chromatography (30\% EtOAc-hexane) to give $\mathbf{1 4}$ (1.67 g, 97\%): colorless needles (benzene-hexane): mp $93{ }^{\circ} \mathrm{C} .[\alpha]_{\mathrm{D}}{ }^{26}-33.19\left(c 0.97, \mathrm{CHCl}_{3}\right) .{ }^{1} \mathrm{H}-\mathrm{NMR}\left(400 \mathrm{MHz}, \mathrm{CDCl}_{3}\right) \delta: 1.05$ (s, 9H), 1.27 (d, $J=$ $7.2 \mathrm{~Hz}, 3 \mathrm{H}$ ), 1.68 (ddt, $J=3.2,3.2,14.8 \mathrm{~Hz}, 1 \mathrm{H}), 1.94(\mathrm{~m}, 1 \mathrm{H}), 1.96$ (m, 1H), 2.44 (ddd, $J=3.6,9.6$, $12.4 \mathrm{~Hz}, 1 \mathrm{H}), 2.89(\mathrm{td}, J=7.2,12.4 \mathrm{~Hz}, 1 \mathrm{H}), 3.94(\mathrm{~m}, 1 \mathrm{H}), 4.39$ (dt, $J=3.6,8.4 \mathrm{~Hz}, 1 \mathrm{H}), 7.26-7.47$ (m, 6H), 7.66-7.68 (m, 4H). ${ }^{13} \mathrm{C}-\mathrm{NMR}\left(100 \mathrm{MHz}, \mathrm{CDCl}_{3}\right) \delta$ : 16.3 (q), 19.1 (s), $26.8(\mathrm{q}), 32.5$ (t), 34.1 (t), 62.5 (t), 73.1 (d), 80.2 (d), 127.2 (d), 127.7 (d), 129.7 (d), 132.6 (s), 132.9 (s), 135.4 (d), 180.4 (s). IR $\left(\mathrm{CHCl}_{3}\right)$ : $3459,1769 \mathrm{~cm}^{-1}$; MS (FAB) m/z: $435\left(\mathrm{M}^{+}+\mathrm{Na}, 100 \%\right)$. Anal. Calcd for $\mathrm{C}_{24} \mathrm{H}_{32} \mathrm{O}_{4} \mathrm{Si}$ : C, 69.86; H, 7.82. Found: C, 69.72; H, 7.85. 
4.2.4.

(3S,5R, 1'R)-5-[1-(tert-Butyldimethylsiloxy)-3-(tert-butyldiphenylsiloxy)propyl]-3-methyldihydrofur an-2-one 31. To a solution of $\mathbf{1 4}(1.37 \mathrm{~g}, 3.33 \mathrm{mmol})$ in $\mathrm{CH}_{2} \mathrm{Cl}_{2}(6.7 \mathrm{~mL})$ were added imidazole (793 $\mathrm{mg}, 11.7 \mathrm{mmol}), 4$-DMAP $(40.3 \mathrm{mg}, 0.33 \mathrm{mmol})$, and TBSCl $(1.50 \mathrm{~g}, 9.99 \mathrm{mmol})$ at room temperature. The mixture was heated for $10 \mathrm{~h}$ under reflux. After addition of water, the resulting mixture was extracted with $\mathrm{CH}_{2} \mathrm{Cl}_{2}$, and the combined organic layers were washed with brine, and dried over $\mathrm{MgSO}_{4}$. After the mixture was evaporated, the residue was purified by silica gel column chromatography (10-30\% EtOAc-hexane) to give $\mathbf{3 1}$ as a colorless oil (1.75 g, quant.). [ $\alpha]_{\mathrm{D}}{ }^{26}-15.6$ $\left(\mathrm{c}=1.16, \mathrm{CHCl}_{3}\right)$, enantiomer; $[\alpha]_{\mathrm{D}}{ }^{20}+13.09\left(\mathrm{c}=0.84, \mathrm{CHCl}_{3}\right) .{ }^{1} \mathrm{H}-\mathrm{NMR}\left(400 \mathrm{MHz}, \mathrm{CDCl}_{3}\right) \delta: 0.05$ (s, 3H), 0.09 (s, 3H), $0.86(\mathrm{~s}, 9 \mathrm{H}), 1.05(\mathrm{~s}, 9 \mathrm{H}), 1.24(\mathrm{~d}, J=7.2 \mathrm{~Hz}, 3 \mathrm{H}), 1.66-1.74(\mathrm{~m}, 1 \mathrm{H})$, 1.78-1.89 (m, 2H), $2.21(\mathrm{ddd}, J=4.4 \mathrm{~Hz}, 9.2 \mathrm{~Hz}, 12.8 \mathrm{~Hz}, 1 \mathrm{H}), 2.65-2.75(\mathrm{~m}, 1 \mathrm{H}), 3.76(\mathrm{t}, J=6.0$ $\mathrm{Hz}, 2 \mathrm{H}), 3.92(\mathrm{dt}, J=4.0 \mathrm{~Hz}, 6.4 \mathrm{~Hz}, 1 \mathrm{H}), 4.43(\mathrm{dt}, J=4.4 \mathrm{~Hz}, 8.4 \mathrm{~Hz}, 1 \mathrm{H}), 7.36-7.46(\mathrm{~m}, 6 \mathrm{H}), 7.64$ (dd, $J=1.2 \mathrm{~Hz}, 6.4 \mathrm{~Hz}, 4 \mathrm{H}) .{ }^{13} \mathrm{C}-\mathrm{NMR}\left(100 \mathrm{MHz}, \mathrm{CDCl}_{3}\right) \delta:-4.5$ (q), -4.4 (q), 16.6 (q), 18.1 (s), 19.2 (s), 25.9 (q), 26.9 (q), 32.2 (t), $34.3(\mathrm{~d}), 35.7$ (t), 60.1 (t), 71.5 (d), 79.1 (d), $127.6(\mathrm{~d}), 129.6(\mathrm{~d})$, 129.7 (d), 133.4 (s), 133.5 (s), 135.4 (d), 180.1 (s). IR (KBr, neat): $1779 \mathrm{~cm}^{-1}$. MS (EI) m/z: 526 $\left(\mathrm{M}^{+}\right), 135$ (100\%). HRMS (EI) Calcd for $\mathrm{C}_{30} \mathrm{H}_{46} \mathrm{O}_{4} \mathrm{Si}_{2}\left(\mathrm{M}^{+}\right)$526.2935, Found: 526.2915.

4.2.5. (3S,5R, I'R)-5-[1-(tert-Butyldimethylsiloxy)-3-hydroxypropyl]-3-methyldihydrofuran-2-one 32. TBAF (1.0 M in THF, $0.02 \mathrm{~mL}, 0.02 \mathrm{mmol})$ and $\mathrm{AcOH}(0.01 \mathrm{~mL}, 0.019 \mathrm{mmol})$ were added to a solution of $31(10 \mathrm{mg}, 0.02 \mathrm{mmol})$ in THF $(0.1 \mathrm{~mL})$ and $\mathrm{CH}_{2} \mathrm{Cl}_{2}(0.1 \mathrm{~mL})$. The resulting mixture was refluxed for $6 \mathrm{~h}$, and saturated aqueous $\mathrm{NaHCO}_{3}$ was added to neutralize the mixture to a $\mathrm{pH}$ of 7 . The aqueous phase was saturated with $\mathrm{NaCl}$ and extracted with EtOAc. The combined organic layers were dried over $\mathrm{MgSO}_{4}$. The solvent was removed in vacuo and the residue was purified by column chromatography (30-75\% EtOAc-hexane) to give 32 as a colorless oil $(4.6 \mathrm{mg}, 84 \%)$. [ $\alpha]_{\mathrm{D}}{ }^{26}-23.7(c$ $\left.1.00, \mathrm{CHCl}_{3}\right)$, enantiomer; $[\alpha]_{\mathrm{D}}{ }^{20}+17.24\left(c 1.45, \mathrm{CHCl}_{3}\right) .{ }^{1} \mathrm{H}-\mathrm{NMR}\left(400 \mathrm{MHz}, \mathrm{CDCl}_{3}\right) \delta: 0.11(\mathrm{~s}$, $3 \mathrm{H}), 0.12(\mathrm{~s}, 3 \mathrm{H}), 0.90(\mathrm{~s}, 9 \mathrm{H}), 1.28(\mathrm{~d}, J=7.2 \mathrm{~Hz}, 3 \mathrm{H}), 1.68-1.76(\mathrm{~m}, 2 \mathrm{H}), 1.84-1.97(\mathrm{~m}, 2 \mathrm{H}), 2.28$ (ddd, $J=4.4 \mathrm{~Hz}, 9.6 \mathrm{~Hz}, 13.2 \mathrm{~Hz}, 1 \mathrm{H}), 2.68-2.78(\mathrm{~m}, 1 \mathrm{H}), 3.73-3.83(\mathrm{~m}, 2 \mathrm{H}), 3.94(\mathrm{dt}, J=6.4 \mathrm{~Hz}$, $10.8 \mathrm{~Hz}, 1 \mathrm{H}), 4.55$ (dt, $J=4.4 \mathrm{~Hz}, 8.8 \mathrm{~Hz}, 1 \mathrm{H}) .{ }^{13} \mathrm{C}-\mathrm{NMR}\left(100 \mathrm{MHz}, \mathrm{CDCl}_{3}\right) \delta:-4.6$ (q), -4.5 (q), 16.5 (q), 18.0 (s), 25.8 (q), 32.0 (t), 34.3 (d), 35.4 (t), 58.8 (t), 71.9 (d), 79.4 (d), 180.1 (s). IR (KBr, neat) 3444, $1770 \mathrm{~cm}^{-1}$. MS (EI) m/z: $288\left(\mathrm{M}^{+}\right), 157$ (100\%). HRMS (EI) Calcd for $\mathrm{C}_{14} \mathrm{H}_{28} \mathrm{O}_{4} \mathrm{Si}\left(\mathrm{M}^{+}\right)$ 288.1757, Found: 288.1744.

4.2.6. (3S,5R, I'R)-5-[1-(tert-Butyldimethylsiloxy)-3-iodopropyl]-3-methyldihydrofuran-2-one 33 To a solution of $32(3.70 \mathrm{~g}, 12.8 \mathrm{mmol})$ in $\mathrm{CH}_{2} \mathrm{Cl}_{2}(128 \mathrm{~mL})$ were added $\mathrm{Et}_{3} \mathrm{~N}(3.6 \mathrm{~mL}, 25.6 \mathrm{mmol})$ and $\mathrm{MsCl}(1.9 \mathrm{~mL}, 19.2 \mathrm{mmol})$. The mixture was stirred for $30 \mathrm{~min}$ at room temperature, and then cooled to $0{ }^{\circ} \mathrm{C}$. Water was added to the resulting mixture, which was diluted with $\mathrm{CH}_{2} \mathrm{Cl}_{2}$. The 
organic layer was washed with $5 \%$ aqueous $\mathrm{HCl}$ and saturated aqueous $\mathrm{NaHCO}_{3}$, and was dried over $\mathrm{MgSO}_{4}$. The solvent was removed in vacuo and the residue was dissolved in acetone (128 mL). NaI $11.5 \mathrm{~g}, 76.8 \mathrm{mmol}$ ) was added to the resulting mixture, which was stirred for $0.5 \mathrm{~h}$ at room temperature. The solvent was removed and water was added. The resulting mixture was extracted with $\mathrm{CH}_{2} \mathrm{Cl}_{2}$, and the combined organic layers were washed with saturated aqueous $\mathrm{Na}_{2} \mathrm{~S}_{2} \mathrm{O}_{4}$ and brine, then dried over $\mathrm{MgSO}_{4}$. After removal of the solvent in vacuo, the residue was purified by column chromatography (10\% EtOAc-hexane) to give a colorless oil $\mathbf{3 3}\left(5.10 \mathrm{mg}\right.$, quant.). $[\alpha]_{\mathrm{D}}{ }^{26}$ -18.1 (c 1.06, $\left.\mathrm{CHCl}_{3}\right)$, enantiomer; $[\alpha]_{\mathrm{D}}{ }^{20}+18.62\left(c\right.$ 1.02, $\left.\mathrm{CHCl}_{3}\right){ }^{1} \mathrm{H}-\mathrm{NMR}\left(400 \mathrm{MHz}, \mathrm{CDCl}_{3}\right) \delta$ : $0.13(\mathrm{~s}, 6 \mathrm{H}), 0.89(\mathrm{~s}, 9 \mathrm{H}), 1.28(\mathrm{~d}, J=7.6 \mathrm{~Hz}, 3 \mathrm{H}), 1.90-2.01(\mathrm{~m}, 2 \mathrm{H}), 2.08-2.16(\mathrm{~m}, 1 \mathrm{H}), 2.30$ (ddd, $J=4.4 \mathrm{~Hz}, 9.6 \mathrm{~Hz}, 12.8 \mathrm{~Hz}, 1 \mathrm{H}), 2.68-2.78(\mathrm{~m}, 1 \mathrm{H}), 3.19-3.28(\mathrm{~m}, 2 \mathrm{H}), 3.85(\mathrm{dt}, J=4.4 \mathrm{~Hz}, 6.8 \mathrm{~Hz}$, $1 \mathrm{H}), 4.47(\mathrm{dt}, J=4.0 \mathrm{~Hz}, 8.0 \mathrm{~Hz}, 1 \mathrm{H}){ }^{13} \mathrm{C}-\mathrm{NMR}\left(100 \mathrm{MHz}, \mathrm{CDCl}_{3}\right) \delta:-4.4(\mathrm{q}),-4.3(\mathrm{q}), 1.7(\mathrm{t}), 16.5$ (q), $18.0(\mathrm{~s}), 25.8$ (q), 31.8 (t), 34.1 (d), 36.4 (t), 74.0 (d), 78.3 (d), 179.6 (s). IR (KBr, neat): 1774 $\mathrm{cm}^{-1}$. MS (EI) m/z: $398\left(\mathrm{M}^{+}\right), 283(100 \%)$. HRMS (EI) Calcd for $\mathrm{C}_{14} \mathrm{H}_{27} \mathrm{O}_{3} \mathrm{SiI}\left(\mathrm{M}^{+}\right)$398.0774, Found: 398.0780 .

4.2.7. ( $1 R, 4 R, 5 R, 7 S)$-4-(tert-Butyldimethylsilyloxy)-7-methyl-8-oxabicyclo[3.2.1]octan-1-ol 34. To a solution of $\mathbf{3 3}(5.10 \mathrm{~g}, 12.8 \mathrm{mmol})$ in THF $(213 \mathrm{~mL})$ was added $t$-BuLi (1.45 M in pentane, 21.2 $\mathrm{mL}, 30.7 \mathrm{mmol}$ ) at $-78{ }^{\circ} \mathrm{C}$. The mixture was stirred for $30 \mathrm{~min}$, and saturated aqueous $\mathrm{NH}_{4} \mathrm{Cl}$ was added. The resulting mixture was extracted with EtOAc, and the combined organic layers were washed with brine and dried over $\mathrm{MgSO}_{4}$. The solvent was removed in vacuo and the residue was purified by column chromatography (15\% EtOAc-hexane) to give $\mathbf{3 4}(3.29 \mathrm{mg}, 94 \%)$ as a colorless solid. ${ }^{1} \mathrm{H}-\mathrm{NMR}\left(400 \mathrm{MHz}, \mathrm{CDCl}_{3}\right)$ $\delta: 0.03$ (s, $\left.1.5 \mathrm{H}\right), 0.04$ (s, $\left.1.5 \mathrm{H}\right), 0.155(\mathrm{~s}, 1.5 \mathrm{H}), 0.12(\mathrm{~s}, 1.5 \mathrm{H})$, $0.86(\mathrm{~s}, 4.5 \mathrm{H}), 0.91(\mathrm{~s}, 4.5 \mathrm{H}), 1.00(\mathrm{~d}, J=6.8 \mathrm{~Hz}, 1.5 \mathrm{H}), 1.10(\mathrm{~d}, J=6.8 \mathrm{~Hz}, 1.5 \mathrm{H}), 1.43-1.52$ (m, 2H), 1.69-1.85 (m, 2H), $1.94(\mathrm{tt}, J=3.2 \mathrm{~Hz}, 14.4 \mathrm{~Hz}, 1 \mathrm{H}), 2.08-2.15(\mathrm{~m}, 0.5 \mathrm{H}), 2.34$ (dd, $J=9.2 \mathrm{~Hz}$, $13.2 \mathrm{~Hz}, 0.5 \mathrm{H}), 2.36-2.43(\mathrm{~m}, 0.5 \mathrm{H}), 2.49$ (dd, $J=3.6 \mathrm{~Hz}, 12.8 \mathrm{~Hz}, 0.5 \mathrm{~Hz}), 2.56$ (s, 0.5 H), 2.70 (s, $0.5 \mathrm{H}), 3.40(\mathrm{dt}, J=3.6 \mathrm{~Hz}, 10.4 \mathrm{~Hz}, 0.5 \mathrm{H}), 3.50$ (ddd, $J=3.2 \mathrm{~Hz}, 7.6 \mathrm{~Hz}, 11.2 \mathrm{~Hz}, 0.5 \mathrm{H}$ ), 3.96-4.00 (m, 0.5 H). ${ }^{13} \mathrm{C}-\mathrm{NMR}\left(100 \mathrm{MHz}, \mathrm{CDCl}_{3}\right) \delta:-4.7$ (q), -4.7 (q), -4.6 (q), -4.1 (q), 17.3 (q), $17.6(\mathrm{q}), 18.0(\mathrm{~s}), 25.8(\mathrm{q}), 27.1(\mathrm{t}), 29.7(\mathrm{t}), 32.5(\mathrm{t}), 35.3(\mathrm{t}), 36.5(\mathrm{t}), 36.6(\mathrm{~d}), 37.6(\mathrm{t}), 41.7(\mathrm{~d})$, 68.0 (d), 76.0 (d), 76.4 (d), 78.6 (d), 104.1 (s), 214.0 (s). IR (0.2mm KBr, $\left.\mathrm{CHCl}_{3}\right): 3590,1701 \mathrm{~cm}^{-1}$; MS (EI) m/z: $272\left(\mathrm{M}^{+}\right), 215(100 \%)$; HRMS (EI) Calcd for $\mathrm{C}_{14} \mathrm{H}_{28} \mathrm{O}_{3} \mathrm{Si}\left(\mathrm{M}^{+}\right)$272.1808, Found: 398.0780 .

4.2.8. 5-(tert-Butyldimethylsiloxy)-4-(tert-butyldiphenylsiloxy)-2-methylcycloheptanone 36. To a solution of $34(11.4 \mathrm{mg}, 0.04 \mathrm{mmol})$ in $\mathrm{CH}_{2} \mathrm{Cl}_{2}(0.08 \mathrm{~mL})$ were added imidazole $(5.1 \mathrm{mg}, 0.07$ mmol), 4-DMAP (catalytic amount), and TBDPSCl $(0.01 \mathrm{~mL}, 0.05 \mathrm{mmol})$ at room temperature. The mixture was stirred for $2 \mathrm{~d}$, and after addition of $\mathrm{H}_{2} \mathrm{O}$, the resulting mixture was extracted with 
$\mathrm{CH}_{2} \mathrm{Cl}_{2}$. The combined organic layers were washed with brine and dried over $\mathrm{MgSO}_{4}$. The solvent was removed in vacuo and the residue was purified by column chromatography (3\% EtOAc-hexane) to give a colorless oil $36(20 \mathrm{mg}, 94 \%)$. $[\alpha]_{\mathrm{D}}{ }^{26}-0.75\left(\mathrm{c}=1.06, \mathrm{CHCl}_{3}\right)$, enantiomer; $[\alpha]_{\mathrm{D}}{ }^{20}+0.96(\mathrm{c}$ 1.04, $\mathrm{CHCl}_{3}$ ); ${ }^{1} \mathrm{H}-\mathrm{NMR}\left(400 \mathrm{MHz}, \mathrm{CDCl}_{3}\right) \delta:-0.31$ (s, 3H), -0.20 (s, 3H), 0.77 (s, 9H), 1.05 (s, 9H), $1.15(\mathrm{~d}, J=6.8 \mathrm{~Hz}, 3 \mathrm{H}), 1.59-1.69(\mathrm{~m}, 2 \mathrm{H}), 1.98-2.06(\mathrm{~m}, 1 \mathrm{H}), 2.28-2.35(\mathrm{~m}, 2 \mathrm{H}), 2.51-2.60(\mathrm{~m}$, 1H), 2.72 (ddd, $J=3.2 \mathrm{~Hz}, 11.6 \mathrm{~Hz}, 12.8 \mathrm{~Hz}, 1 \mathrm{H}), 3.51(\mathrm{dt}, J=2.4 \mathrm{~Hz}, 5.6 \mathrm{~Hz}, 1 \mathrm{H}), 3.94$ (ddd, $J=$ $2.0 \mathrm{~Hz}, 4.8 \mathrm{~Hz}, 7.2 \mathrm{~Hz}, 1 \mathrm{H}), 7.35-7.47(\mathrm{~m}, 6 \mathrm{H}), 7.65$ (dd, $J=1.2 \mathrm{~Hz}, 8.0 \mathrm{~Hz}, 4 \mathrm{H}) .{ }^{13} \mathrm{C}-\mathrm{NMR}$ $\left(100 \mathrm{MHz}, \mathrm{CDCl}_{3}\right)$ 8: -5.1 (q), -5.0 (q), $17.9(\mathrm{q}), 18.2(\mathrm{~s}), 19.2(\mathrm{~s}), 25.7(\mathrm{q}), 27.2(\mathrm{q}), 27.2(\mathrm{t}), 32.1(\mathrm{t})$, 36.6 (t), 42.6 (d), 71.7 (d), 74.8 (d), 127.6 (d), 127.7 (d), 129.7 (d), 129.7 (d), 133.8 (s), 133.9 (s), 135.7 (d), 135.8 (d), 213.5 (s). IR (KBr, neat) $1711 \mathrm{~cm}^{-1}$; MS (EI) m/z: 510(M+), 193 (100\%); HRMS (EI) Calcd for $\mathrm{C}_{30} \mathrm{H}_{46} \mathrm{O}_{3} \mathrm{Si}_{2}\left(\mathrm{M}^{+}\right)$510.2986, Found: 510.3013 .

4.2.9. (1S,2S,4R,5R)-5-(tert-Butyldimethylsilyloxy)-4-(tert-butyldiphenylsilyloxy)-2-methyl-1vinylcycloheptanol 39. To a $1.0 \mathrm{M}$ THF solution of vinylmagnesium bromide $(3.5 \mathrm{~mL}, 3.51 \mathrm{mmol})$ was added $36(0.89 \mathrm{~g}, 1.75 \mathrm{mmol})$ in THF $(6.0 \mathrm{~mL})$, and the mixture was refluxed for $6 \mathrm{~h}$. After cooling to room temperature, the mixture was poured into $0.3 \mathrm{M} \mathrm{HCl}$ at $0{ }^{\circ} \mathrm{C}$. The mixture was extracted with EtOAc, and the combined organic layers were washed with saturated aqueous $\mathrm{NaHCO}_{3}$, and brine, and dried over $\mathrm{MgSO}_{4}$. The solvent was removed in vacuo and the residue was purified by column chromatography (5\% EtOAc-Hexane), to give $\mathbf{3 9}$ as a colorless oil ( $0.90 \mathrm{~g}, 96 \%)$. $[\alpha]_{\mathrm{D}}{ }^{26}-12.58$ (c 1.04, $\mathrm{CHCl}_{3}$ ), enantiomer; $[\alpha]_{\mathrm{D}}{ }^{20}+14.96$ (c 1.47, $\left.\mathrm{CHCl}_{3}\right) ;{ }^{1} \mathrm{H}-\mathrm{NMR}(400 \mathrm{MHz}$, $\left.\mathrm{CDCl}_{3}\right) \delta:-0.23$ (s, 3H), -0.12 (s, 3H), $0.80(\mathrm{~s}, 9 \mathrm{H}), 1.09$ (s, 9H), 1.41-1.52 (m, 2H), 1.65-1.75 (m, $3 \mathrm{H}), 1.87(\mathrm{~m}, 1 \mathrm{H}), 2.17(\mathrm{~m}, 1 \mathrm{H}), 2.91(\mathrm{~s}, 1 \mathrm{H}), 3.62(\mathrm{~m}, 1 \mathrm{H}), 3.86(\mathrm{~m}, 1 \mathrm{H}), 4.95(\mathrm{dd}, J=1.6 \mathrm{~Hz}, 10.8$ $\mathrm{Hz}, 1 \mathrm{H}), 5.17$ (dd, $J=1.6 \mathrm{~Hz}, 17.2 \mathrm{~Hz}, 1 \mathrm{H}), 5.77$ (dd, $J=10.8 \mathrm{~Hz}, 17.2 \mathrm{~Hz}, 1 \mathrm{H}), 7.34-7.45(\mathrm{~m}, 6 \mathrm{H})$, 7.67-7.71 (m, 4H). ${ }^{13} \mathrm{C}-\mathrm{NMR}\left(100 \mathrm{MHz}, \mathrm{CDCl}_{3}\right)$ 8: -4.8 (q), -4.7 (q), 17.9 (q), 18.5 (s), 19.1 (s), 25.8 $(\mathrm{q}), 26.0(\mathrm{t}), 27.1(\mathrm{q}), 35.1(\mathrm{t}), 36.2(\mathrm{t}), 38.4(\mathrm{~d}), 73.8(\mathrm{~d}), 75.7(\mathrm{~s}), 76.6(\mathrm{~d}), 109.8(\mathrm{t}), 127.5(\mathrm{~d})$, 127.6 (d), 129.6 (d), 129.7 (d), 133.5 (s), 133.7 (s), 135.8 (d), 135.9 (d), 146.2 (d). IR (KBr, neat): 3464, $1704 \mathrm{~cm}^{-1}$; MS (ESI) m/z: $561\left(\mathrm{M}^{+}+\mathrm{Na}\right)$; HRMS (ESI) Calcd for $\mathrm{C}_{32} \mathrm{H}_{50} \mathrm{O}_{3} \mathrm{NaSi}_{2}\left(\mathrm{M}^{+}+\mathrm{Na}\right)$ 561.3196, Found: 561.3192.

4.2.10. (1S,4R,5R,7S)-5-(tert-Butyldiphenylsilyloxy)-7-methyl-1-vinylcycloheptane-1,4-diol 40. To a solution of $39(1.35 \mathrm{~g}, 1.61 \mathrm{mmol})$ in THF $(14.2 \mathrm{~mL})$ was added $6 \mathrm{M} \mathrm{HCl}(1.8 \mathrm{~mL})$. The mixture was stirred for $18 \mathrm{~h}$ at room temperature, and then extracted with EtOAc. The combined organic layers were washed with saturated aqueous $\mathrm{NaHCO}_{3}$ and brine, and dried over $\mathrm{MgSO}_{4}$. The solvent was removed in vacuo and the residue was purified by column chromatography $(30 \%$ EtOAc-hexane) to give $\mathbf{4 0}$ as colorless needles $(0.62 \mathrm{~g}, 91 \%)$ : (EtOAc-hexane): $\mathrm{mp} 110{ }^{\circ} \mathrm{C} ;[\alpha]_{\mathrm{D}}{ }^{25}$ $-49.55\left(\mathrm{c} 1.12, \mathrm{CHCl}_{3}\right)$, enantiomer; $[\alpha]_{\mathrm{D}}{ }^{20}+53.19\left(c 0.94, \mathrm{CHCl}_{3}\right) ;{ }^{1} \mathrm{H}-\mathrm{NMR}\left(400 \mathrm{MHz}, \mathrm{CDCl}_{3}\right) \delta$ : 
$0.51(\mathrm{~d}, J=6.8 \mathrm{~Hz}, 3 \mathrm{H}), 1.04(\mathrm{~s}, 9 \mathrm{H}), 1.13(\mathrm{~m}, 3 \mathrm{H}), 1.36(\mathrm{~m}, 1 \mathrm{H}), 1.55-1.60(\mathrm{~m}, 1 \mathrm{H}), 1.76-1.83(\mathrm{~m}$, 2H), $1.90(\mathrm{~m}, 1 \mathrm{H}), 2.42(\mathrm{~s}, 1 \mathrm{H}), 3.53(\mathrm{~m}, 1 \mathrm{H}), 3.64(\mathrm{~m}, 1 \mathrm{H}), 4.96(\mathrm{dd}, J=1.2 \mathrm{~Hz}, 11.2 \mathrm{~Hz}, 1 \mathrm{H})$, $5.079(\mathrm{dd}, J=1.2 \mathrm{~Hz}, 17.2 \mathrm{~Hz}, 1 \mathrm{H}), 5.75(\mathrm{dd}, J=11.2 \mathrm{~Hz}, 17.2 \mathrm{~Hz}, 1 \mathrm{H}), 7.40(\mathrm{~m}, 6 \mathrm{H}), 7.66(\mathrm{~m}, 4 \mathrm{H})$. ${ }^{13} \mathrm{C}-\mathrm{NMR}\left(150 \mathrm{MHz}, \mathrm{CDCl}_{3}\right)$ 8: $16.1(\mathrm{q}), 19.3(\mathrm{~s}), 25.3(\mathrm{t}), 27.0(\mathrm{q}), 35.5(\mathrm{t}), 35.7(\mathrm{t}), 36.5(\mathrm{~d}), 75.5$ (s), 78.5 (d), 81.1 (d), 110.9 (d), 127.6 (d), 127.8 (d), 129.7 (d), 129.8 (d), 133.7 (s), 135.6 (d), 135.7 (d), 145.3 (d). IR (0.1 mm NaCl, $\left.\mathrm{CHCl}_{3}\right)$ : 3427, $1633 \mathrm{~cm}^{-1}$; MS (FAB) m/z: $425\left(\mathrm{M}^{+}+1\right)$; Anal. Calcd for $\mathrm{C}_{26} \mathrm{H}_{36} \mathrm{O}_{3} \mathrm{Si}$ : C, 73.54; H, 8.54. Found: $\mathrm{C}, 73.47 ; \mathrm{H}, 8.49$.

4.2.11. (1S,2R,4S,5S)-2-(tert-Butyldiphenylsilyloxy)-4-methyl-5-vinyl-8-oxabicyclo[3.2.1] octan-1-ol 41. To a solution of $40(0.62 \mathrm{~g}, 1.46 \mathrm{mmol})$ in $\mathrm{CH}_{2} \mathrm{Cl}_{2}(10 \mathrm{~mL})$ were added 4-methylmorpholine $\mathrm{N}$-oxide $(0.85 \mathrm{~g}, 7.30 \mathrm{mmol})$ and MS4A $(0.73 \mathrm{~g})$. The mixture was stirred at room temperature for 10 $\mathrm{min}$, and tetrapropylammonium perruthenate $(0.02 \mathrm{~g}, 0.07 \mathrm{mmol})$ was added. The mixture was stirred for $1 \mathrm{~h}$, and filtered through a pad of Celite. The solvent was removed from the filtrate and the crude product was purified with column chromatography (30\% EtOAc-hexane) to give $\mathbf{4 1}$ as a colorless oil (0.61 g, quant.). $[\alpha]_{\mathrm{D}}{ }^{25}-40.62$ (c 1.35, $\mathrm{CHCl}_{3}$ ), enantiomer; $[\alpha]_{\mathrm{D}}{ }^{20}+54.54$ (c 0.33 , $\left.\mathrm{CHCl}_{3}\right) ;{ }^{1} \mathrm{H}-\mathrm{NMR}\left(400 \mathrm{MHz}, \mathrm{CDCl}_{3}\right) \delta: 1.09(\mathrm{~s}, 9 \mathrm{H}), 1.13(\mathrm{~d}, J=6.8 \mathrm{~Hz}, 3 \mathrm{H}), 1.46(\mathrm{~m}, 2 \mathrm{H})$, 1.69-1.95 (m, 5H), $3.72(\mathrm{~s}, 1 \mathrm{H}), 3.77(\mathrm{~m}, 1 \mathrm{H}), 5.04(\mathrm{dd}, J=1.48 \mathrm{~Hz}, 11 \mathrm{~Hz}, 1 \mathrm{H}), 5.23(\mathrm{dd}, J=1.48$ $\mathrm{Hz}, 17.5 \mathrm{~Hz}, 1 \mathrm{H}), 5.93(\mathrm{dd}, J=11 \mathrm{~Hz}, 17.5 \mathrm{~Hz}, 1 \mathrm{H}), 7.40(\mathrm{~m}, 6 \mathrm{H}), 7.70(\mathrm{~m}, 4 \mathrm{H}) ;{ }^{13} \mathrm{C}-\mathrm{NMR}$

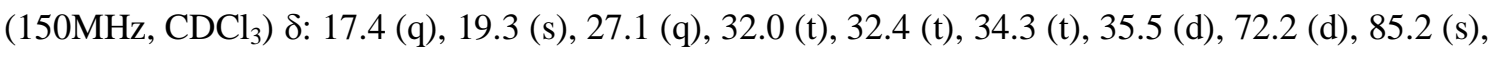
104.3 (s), 112.0 (t), 127.7 (d), 127.9 (d), 129.8 (d), 129.9 (d), 133.1 (s), 133.4 (d), 135.8 (d), 136.2 (d), 141.3 (d); IR (KBr neat): $3551 \mathrm{~cm}^{-1}$; MS (FAB) m/z: $422\left(\mathrm{M}^{+}\right)$: HRMS (FAB) Calcd for $\mathrm{C}_{26} \mathrm{H}_{34} \mathrm{O}_{3} \mathrm{Si}\left(\mathrm{M}^{+}+\mathrm{Na}\right)$ 422.2277, Found: 422.2278 .

4.2.12. (1S,2R,4S,5S)-4-Methyl-5-vinyl-8-oxabicyclo[3.2.1] octane-1,2-diol 42. To a solution of 41 $(0.16 \mathrm{~g}, 1.46 \mathrm{mmol})$ in THF $(15 \mathrm{~mL})$ was added TBAF $(1.0 \mathrm{M}$ in THF, $1.7 \mathrm{~mL})$. The mixture was stirred at room temperature for $30 \mathrm{~min}$, and the solvent was removed in vacuo. The residue was purified with column chromatography (30-60\% EtOAc-hexane) to give $\mathbf{4 2}$ as colorless needles $(0.26$ g, quant.). Colorless needles (EtOAc-hexane): mp 63-64 ${ }^{\circ} \mathrm{C} ;[\alpha]_{\mathrm{D}}^{25}-50.98\left(\mathrm{c}=1.02, \mathrm{CHCl}_{3}\right)$, enantiomer; $[\alpha]_{\mathrm{D}}{ }^{20}+64.38\left(\mathrm{c}=0.73, \mathrm{CHCl}_{3}\right) ; 1 \mathrm{H}-\mathrm{NMR}\left(400 \mathrm{MHz}, \mathrm{CDCl}_{3}\right) \delta: 1.11(\mathrm{~d}, J=7.2 \mathrm{~Hz}$, $3 \mathrm{H}), 1.60(\mathrm{~m}, 1 \mathrm{H}), 1.76(\mathrm{~m}, 1 \mathrm{H}), 1.84-2.00(\mathrm{~m}, 4 \mathrm{H}), 2.04(\mathrm{~m}, 1 \mathrm{H}), 2.16(\mathrm{~m}, 1 \mathrm{H}), 3.60(\mathrm{~m}, 1 \mathrm{H}), 3.88$ (s, 1H), 5.08 (dd, $J=1.2 \mathrm{~Hz}, 11.2 \mathrm{~Hz}, 1 \mathrm{H}), 5.26(\mathrm{dd}, J=1.2 \mathrm{~Hz}, 18 \mathrm{~Hz}, 1 \mathrm{H}), 5.90$ (dd, $J=11.2 \mathrm{~Hz}$, $18 \mathrm{~Hz}) ;{ }^{13} \mathrm{C}-\mathrm{NMR}\left(150 \mathrm{MHz}, \mathrm{CDCl}_{3}\right) \delta: 18.1(\mathrm{q}), 32.1(\mathrm{t}), 32.9(\mathrm{t}), 34.4(\mathrm{t}), 35.1(\mathrm{~d}), 70.9(\mathrm{~d}), 85.4$ (s), 104.5 (s), 112.1 (t), 140.5 (d); IR (0.1 mm NaCl, $\left.\mathrm{CHCl}_{3}\right): 3537 \mathrm{~cm}^{-1} ; \mathrm{MS}$ (FAB) $\mathrm{m} / \mathrm{z}: 185$ $\left(\mathrm{M}^{+}+1\right), 154$ (100\%); Anal. Calcd for $\mathrm{C}_{10} \mathrm{H}_{16} \mathrm{O}_{3}$ : C, 65.19; H, 8.75. Found: C, 65.11; H, 8.72.

4.2.13. 
(6S,7S,8aR)-6-Hydroxy-3,7-dimethyl-6-vinyl-4,5,6,7,8,8a-hexahydro-2 $H$-cyclohepta[b]furan-2-one 46. To a solution of $42(0.10 \mathrm{~g}, 0.54 \mathrm{mmol})$ in xylene $(10.8 \mathrm{~mL})$ was added the Wittig reagent $\left(\mathrm{Ph}_{3} \mathrm{PC}\left(\mathrm{CH}_{3}\right) \mathrm{CO}_{2} \mathrm{CH}_{2} \mathrm{CF}_{3}, 1.80 \mathrm{~g}, 4.32 \mathrm{mmol}\right)$. The resulting mixture was refluxed for $4 \mathrm{~h}$. The solvent was removed and the crude residue was purified with column chromatography (50\% EtOAc-hexane) to give $\mathbf{4 6}$ as colorless prisms $(0.112 \mathrm{~g}, 92 \%)$ : (EtOAc-hexane): $\mathrm{mp} 151^{\circ} \mathrm{C}$; $[\alpha]_{\mathrm{D}}{ }^{25}$ $-140.27\left(c 1.08, \mathrm{CHCl}_{3}\right)$, enantiomer; $[\alpha]_{\mathrm{D}}{ }^{20}+133.11$ ( $c$ 1.54, $\left.\mathrm{CHCl}_{3}\right) ;{ }^{1} \mathrm{H}-\mathrm{NMR}\left(400 \mathrm{MHz}, \mathrm{CDCl}_{3}\right) \delta$ : $0.93(\mathrm{~d}, J=6.8 \mathrm{~Hz}, 3 \mathrm{H}), 1.61(\mathrm{~m}, 1 \mathrm{H}), 1.775(\mathrm{~m}, 1 \mathrm{H}), 1.779(\mathrm{~s}, 3 \mathrm{H}), 1.86(\mathrm{~m}, 2 \mathrm{H}), 2.11(\mathrm{~m}, 1 \mathrm{H})$, $2.53(\mathrm{~m}, 1 \mathrm{H}), 2.89(\mathrm{~m}, 1 \mathrm{H}), 4.87(\mathrm{bd}, J=12.4 \mathrm{~Hz}, 1 \mathrm{H}), 5.09(\mathrm{~d}, J=10.8 \mathrm{~Hz}, 1 \mathrm{H}), 5.19$ (d, $J=17.6$ $\mathrm{Hz}, 1 \mathrm{H}), 5.93(\mathrm{dd}, J=10.8 \mathrm{~Hz}, 17.6 \mathrm{~Hz}, 1 \mathrm{H}) ;{ }^{13} \mathrm{C}-\mathrm{NMR}\left(150 \mathrm{MHz}, \mathrm{CDCl}_{3}\right) \delta: 8.2$ (q), 17.1 (q), 20.8 $(\mathrm{t}), 36.0(\mathrm{t}), 36.3(\mathrm{t}), 39.9(\mathrm{~d}), 75.3(\mathrm{~s}), 82.1(\mathrm{~d}), 110.4(\mathrm{t}), 120.8(\mathrm{~d}), 146.3(\mathrm{~d}), 164.8(\mathrm{~s}), 174.5(\mathrm{~s})$. IR $\left(\mathrm{CHCl}_{3}\right): 3471,1741,1672 \mathrm{~cm}^{-1}$. MS (EI) m/z: $222\left(\mathrm{M}^{+}\right), 204(100 \%)$; Anal. Calcd for $\mathrm{C}_{13} \mathrm{H}_{18} \mathrm{O}_{3}$ : C, 70.24; H, 8.16. Found: C, 70.05; H, 8.12. CCDC-629263 contains the supplementary crystallographic data for this paper. These data can be obtained free of charge via www.ccdc.cam.ac.uk/conts.retrieving.html (or from the Cambridge Crystallographic Data Centre, 12, Union Road, Cambridge CB21EZ, UK; fax: (+44)1223-336-033; or deposit@ccdc.cam.ac.uk).

\subsubsection{4.}

(6R,7S,8aR)-6-Hydroxy-3,7-dimethyl-6-(oxiran-2-yl)-4,5,6,7,8,8a-hexahydro-2 $H$-cyclohepta[b]furan -2-one 48. To a solution of $46(50 \mathrm{mg}, 0.22 \mathrm{mmol})$ in $\mathrm{CH}_{2} \mathrm{Cl}_{2}(2.2 \mathrm{~mL})$ was added $m$-chloroperbenzoic acid $(155.3 \mathrm{mg}, 0.90 \mathrm{mmol})$. The mixture was stirred for $10 \mathrm{~h}$ at room temperature, and then saturated aqueous $\mathrm{NaHCO}_{3}$ and brine were added. The mixture was extracted with $\mathrm{CH}_{2} \mathrm{Cl}_{2}$, and the combined organic layers were washed with brine and dried over $\mathrm{MgSO}_{4}$. The solvent was removed and the crude residue was purified with column chromatography $(60 \%$ EtOAc-hexane) to give $48(50.2 \mathrm{mg}, 96 \%)$ as colorless prisms; $\left(\mathrm{CH}_{2} \mathrm{Cl}_{2}\right.$-hexane); mp. $220{ }^{\circ} \mathrm{C}$; $[\alpha]_{\mathrm{D}}{ }^{22}$ -99.25 (c = 1.35, $\left.\mathrm{CHCl}_{3}\right) ;{ }^{1} \mathrm{H}-\mathrm{NMR}\left(400 \mathrm{MHz}, \mathrm{CDCl}_{3}\right) \delta: 1.01(\mathrm{~d}, J=6.8 \mathrm{~Hz}, 3 \mathrm{H}), 1.39(\mathrm{~s}, 1 \mathrm{H}), 1.67$ (ddd, $J=11.2 \mathrm{~Hz}, 12 \mathrm{~Hz}, 14 \mathrm{~Hz}, 1 \mathrm{H}), 1.77(\mathrm{~s}, 3 \mathrm{H}), 1.81-1.89(\mathrm{~m}, 2 \mathrm{H}), 2.59(\mathrm{~m}, 1 \mathrm{H}), 2.81(\mathrm{~m}, 1 \mathrm{H})$, $2.91(\mathrm{~d}, J=4 \mathrm{~Hz}, 2 \mathrm{H}), 2.98(\mathrm{t}, J=4 \mathrm{~Hz}, 1 \mathrm{H}), 4.89$ (bd, $J=11.2 \mathrm{~Hz}, 1 \mathrm{H}) .{ }^{13} \mathrm{C}-\mathrm{NMR}(100 \mathrm{MHz}$, $\left.\mathrm{CDCl}_{3}\right) \delta: 8.3(\mathrm{q}), 16.7(\mathrm{q}), 20.7(\mathrm{t}), 34.0(\mathrm{t}), 36.7(\mathrm{t}), 38.5(\mathrm{~d}), 46.5(\mathrm{t}), 58.0(\mathrm{~d}), 71.3(\mathrm{~s}), 81.9(\mathrm{~d})$, 121.1 (s), 164.4 (s), 174.4 (s). IR ( $\left.\mathrm{CHCl}_{3}\right)$ : 3018, $1743 \mathrm{~cm}^{-1}$. MS (EI) m/z: $238\left(\mathrm{M}^{+}\right), 177$ (100\%); Anal. Calcd for $\mathrm{C}_{13} \mathrm{H}_{18} \mathrm{O}_{4}$ : C, 66.53; H, 7.61. Found: C, 65.26; H, 7.58.

4.2.15. (3S,3aR,6R,7S,8aR)-6-Hydroxy-3,7-dimethyl-6-(oxiran-2-yl)octahydro-2H-cyclohepta[ $b$ ] furan-2-one 49. To a suspension of $48(139 \mathrm{mg}, 0.58 \mathrm{mmol})$ and $\mathrm{NiCl}_{2}(19 \mathrm{mg}, 0.14 \mathrm{mmol})$ in $\mathrm{MeOH}(10 \mathrm{~mL})$ was added $\mathrm{NaBH}_{4}(88 \mathrm{mg}, 2.34 \mathrm{mmol})$ at $0{ }^{\circ} \mathrm{C}$. The mixture was stirred at $0{ }^{\circ} \mathrm{C}$ for 2 $\mathrm{h}$, and then saturated aqueous $\mathrm{NH}_{4} \mathrm{Cl}(5 \mathrm{~mL})$ was added. The resulting mixture was diluted with $\mathrm{CH}_{2} \mathrm{Cl}_{2}$ and the aqueous layer was extracted with $\mathrm{CH}_{2} \mathrm{Cl}_{2}$. The combined organic layers were washed 
with brine and dried over $\mathrm{MgSO}_{4}$. The solvent was removed and the crude residue was purified by HPLC (60\% EtOAc-hexane) to give 49 as colorless prisms (114 mg, 81\%, 4:1 mixture of diastereomers of the oxirane) and C11-isomer (14\%). Major isomer of 49: colorless prisms $\left(\mathrm{CH}_{2} \mathrm{Cl}_{2}\right.$-hexane); $\mathrm{mp} 150{ }^{\circ} \mathrm{C} ;[\alpha]_{\mathrm{D}}{ }^{22}-5.00\left(c 1.00, \mathrm{CHCl}_{3}\right) ;{ }^{1} \mathrm{H}-\mathrm{NMR}\left(400 \mathrm{MHz}, \mathrm{CDCl}_{3}\right) \delta: 1.00(\mathrm{~d}, J$ $=7.2 \mathrm{~Hz}, 3 \mathrm{H}), 1.20(\mathrm{~d}, J=7.2 \mathrm{~Hz}, 3 \mathrm{H}), 1.45-1.59(\mathrm{~m}, 2 \mathrm{H}), 1.72(\mathrm{~m}, 3 \mathrm{H}), 2.02(\mathrm{ddd}, J=7.6 \mathrm{~Hz}, 7.6$ $\mathrm{Hz}, 8.0 \mathrm{~Hz}, 1 \mathrm{H}), 2.35$ (ddd, $J=10.4 \mathrm{~Hz}, 11.2 \mathrm{~Hz}, 14.8 \mathrm{~Hz}, 1 \mathrm{H}), 2.58(\mathrm{~m}, 1 \mathrm{H}), 2.78-2.87$ (m, 3H), $2.93(\mathrm{dd}, J=2.8 \mathrm{~Hz}, 5.2 \mathrm{~Hz}, 1 \mathrm{H}), 4.67(\mathrm{ddd}, J=6.6 \mathrm{~Hz}, 12 \mathrm{~Hz}, 1 \mathrm{H}) ;{ }^{13} \mathrm{C}-\mathrm{NMR}\left(100 \mathrm{MHz}, \mathrm{CDCl}_{3}\right) \delta$ : 11.1 (q), 17.3 (t), 17.8 (q), 33.2 (t), 34.5 (d), 38.9 (d), 40.9 (t), 43.4 (d), 45.1 (t), 58.3 (d), 71.2 (s), 80.8 (r), 179.1 (s). IR (0.1 mm NaCl, $\left.\mathrm{CHCl}_{3}\right): 1762 \mathrm{~cm}^{-1}$. MS (FAB) m/z: $241\left(\mathrm{M}^{+}+1\right)$; Anal. Calcd for $\mathrm{C}_{13} \mathrm{H}_{20} \mathrm{O}_{4}$ : C, 64.98; H, 8.39. Found: C, 64.93; H, 8.36.

4.2.16. (3S,3aR,7S, 8aR)-3,7-Dimethyl-6-(oxiran-2-yl)-3,3a,4,7,8,8a-hexahydro-2H-cyclohepta[b] furan-2-one 50. To a solution of $49(3.0 \mathrm{mg}, 0.0125 \mathrm{mmol})$ in $\mathrm{CH}_{2} \mathrm{Cl}_{2}(1.2 \mathrm{~mL})$ was added dropwise a solution of freshly distilled thionyl chloride $(1.8 \mu \mathrm{L}, 0.025 \mathrm{mmol})$ and pyridine $(4 \mu \mathrm{L})$ in $\mathrm{CH}_{2} \mathrm{Cl}_{2}$ $(0.3 \mathrm{~mL})$ at $-20^{\circ} \mathrm{C}$. The resulting mixture was stirred at $-20^{\circ} \mathrm{C}$ for $10 \mathrm{~min}$ then saturated aqueous $\mathrm{NaHCO}_{3}$ was added. The resulting mixture was extracted with $\mathrm{CH}_{2} \mathrm{Cl}_{2}$, and the combined organic layer was washed with aqueous $\mathrm{CuSO}_{4}$ and dried over $\mathrm{MgSO}_{4}$. The solvent was removed in vacuo and the residue was purified by column chromatography (20\% EtOAc-hexane) to give $\mathbf{5 0}$ as a colorless oil (2.5 mg, 87\%); Major isomer: $\mathrm{mp} .71 .5-72{ }^{\circ} \mathrm{C}$ (hexane-EtOAc); $[\alpha]_{\mathrm{D}}{ }^{22}-16.22^{\circ}(c 0.31$, $\left.\mathrm{CHCl}_{3}\right) ;{ }^{1} \mathrm{H}-\mathrm{NMR}\left(400 \mathrm{MHz}, \mathrm{CDCl}_{3}\right) \delta: 1.16(\mathrm{~d}, J=7.2 \mathrm{~Hz}, 3 \mathrm{H}), 1.20(\mathrm{~d}, J=6.8 \mathrm{~Hz}, 3 \mathrm{H}), 1.95-2.19$ $(\mathrm{m}, 4 \mathrm{H}), 2.47(\mathrm{dd}, J=6.4 \mathrm{~Hz}, 3.2 \mathrm{~Hz}, 1 \mathrm{H}), 2.48(\mathrm{~m}, 1 \mathrm{H}), 2.73(\mathrm{~m}, 1 \mathrm{H}), 2.83(\mathrm{~m}, 1 \mathrm{H}), 2.91(\mathrm{dd}, J=$ $6.4 \mathrm{~Hz}, 4.4 \mathrm{~Hz}, 1 \mathrm{H}), 3.23$ (bs, 1H), 4.65 (m, 1H), 5.73 (bd, $J=9.6 \mathrm{~Hz}, 1 \mathrm{H}),{ }^{13} \mathrm{C}-\mathrm{NMR}(100 \mathrm{MHz}$, $\left.\mathrm{CDCl}_{3}\right) \delta: 10.6(\mathrm{q}), 21.0(\mathrm{q}), 31.8(\mathrm{t}), 36.9$ (d), 38.9 (d), 42.3 (t), 50.4 (d), 52.7 (d), $53.2(\mathrm{~d}), 80.1(\mathrm{t})$, 121.4 (d), 141.2 (s), 178.8 (s). IR ( $\mathrm{NaCl}$, neat): $1770 \mathrm{~cm}^{-1}$. MS (EI) m/z: $222\left(\mathrm{M}^{+}\right), 60$ (100\%); HRMS (EI) Calcd for $\mathrm{C}_{13} \mathrm{H}_{18} \mathrm{O}_{3}\left(\mathrm{M}^{+}\right)$222.1256, Found: 222.1258 .

4.2.17. Sundiversifolide (4). To a solution of $\mathbf{5 0}(18.6 \mathrm{mg}, 0.0837 \mathrm{~mol})$ in $\mathrm{CH}_{2} \mathrm{Cl}_{2}(1.5 \mathrm{~mL})$ and THF $(0.1 \mathrm{~mL})$ was added $\mathrm{ZnI}_{2}(80.1 \mathrm{mg}, 0.25 \mathrm{mmol})$ and $\mathrm{NaBH}_{3} \mathrm{CN}(16.5 \mathrm{mg}, 0.25 \mathrm{mmol})$. The mixture was stirred for $2 \mathrm{~h}$ at room temperature, and $1 \mathrm{M}$ aqueous $\mathrm{HCl}(0.1 \mathrm{~mL})$ was added at $0{ }^{\circ} \mathrm{C}$. The resulting mixture was saturated with $\mathrm{NaCl}$ and extracted with $\mathrm{CH}_{2} \mathrm{Cl}_{2}$. The organic layer was dried over $\mathrm{MgSO}_{4}$. The solvent was removed in vacuo and the residue was purified by column chromatography (70\% EtOAc-hexane) to give 4 as a colorless solid $(15.9 \mathrm{mg}, 85 \%)$. mp. $42-47^{\circ} \mathrm{C}$; $[\alpha]_{\mathrm{D}}{ }^{20}+33.0\left(c\right.$ 0.44, $\mathrm{CHCl}_{3}$ ), enantiomer; $[\alpha]_{\mathrm{D}}{ }^{20}-33.7^{\circ}$ (c $\left.0.46, \mathrm{CHCl}_{3}\right) ;{ }^{1} \mathrm{H}-\mathrm{NMR}(400 \mathrm{MHz}$, $\left.\mathrm{CD}_{3} \mathrm{OD}\right) \delta: 1.11(\mathrm{~d}, J=7.3 \mathrm{~Hz}, 3 \mathrm{H}), 1.15(\mathrm{~d}, J=7.1 \mathrm{~Hz}, 3 \mathrm{H}), 1.87-1.99(\mathrm{~m}, 2 \mathrm{H}), 2.01-2.04(\mathrm{~m}, 2 \mathrm{H})$, 2.10-2.23 (m, 2H), 2.72-2.80 (m, 1H), 2.86-2.94 (m, 1H), 3.50-3.63 (m, 2H), 4.67-4.73 (m, $1 \mathrm{H})$, 5.53-5.55 (m, 1H). ${ }^{13} \mathrm{C}-\mathrm{NMR}\left(150 \mathrm{MHz}, \mathrm{CD}_{3} \mathrm{OD}\right) \delta: 10.9,21.8,22.8,33.9,38.2,40.1,41.2,43.5$, 
62.1, 82.5, 125.3, 143.6, 181.8; IR (neat): $3415,1651,1732 \mathrm{~cm}^{-1}$. HRMS (EI) Calcd for $\mathrm{C}_{13} \mathrm{H}_{20} \mathrm{O}_{3}$ $\left(\mathrm{M}^{+}\right)$224.1412, Found 224.1405.

\subsection{Synthesis of 5}

4.3.1. (3S,3a R,7S,8aR)-3,7-Dimethyl-6-vinyl-3,3a,4,7,8,8a-hexahydro-2H-cyclohepta[b]furan-2-one 5. To a solution of the epoxide $\mathbf{5 0}(6.2 \mathrm{mg}, 27.9 \mu \mathrm{mol})$ in $\mathrm{H}_{2} \mathrm{O} /$ methanol $(1: 10,0.3 \mathrm{~mL})$ was added potassium selenocyanate $(16.1 \mathrm{mg}, 111.6 \mu \mathrm{mol})$. The mixture was stirred for $10 \mathrm{~h}$ at room temperature. The reaction was filtered, diluted with water, and extracted with $\mathrm{Et}_{2} \mathrm{O}$. The combined organic layers were washed with brine and dried over $\mathrm{MgSO}_{4}$. After the mixture was evaporated, the residue was purified by silica gel column chromatography (10\% EtOAc/Hex) to give 5 (5.2 mg, 90\%) as colorless prisms: mp 53.0-54.0 ${ }^{\circ} \mathrm{C}$ (EtOAc-Hex); $[\alpha]_{\mathrm{D}}{ }^{21}-21.21$ (c 0.33, $\left.\mathrm{CHCl}_{3}\right) ;{ }^{1} \mathrm{H}-\mathrm{NMR}$ $\left(600 \mathrm{MHz}, \mathrm{CDCl}_{3}\right) \delta: 1.19(\mathrm{~d}, J=6.6 \mathrm{~Hz}, 3 \mathrm{H}), 1.23(\mathrm{~d}, J=4.8 \mathrm{~Hz}, 3 \mathrm{H}), 1.98-2.05(\mathrm{~m}, 2 \mathrm{H}), 2.16$ (ddd, $J=13.8 \mathrm{~Hz}, 5.4 \mathrm{~Hz}, 3.6 \mathrm{~Hz}, 1 \mathrm{H}), 2.43-2.48(\mathrm{~m}, 1 \mathrm{H}), 2.71-2.86(\mathrm{~m}, 3 \mathrm{H}), 4.63$ (ddd, $J=11.4 \mathrm{~Hz}$, $7.2 \mathrm{~Hz}, 3.6 \mathrm{~Hz}, 1 \mathrm{H}), 4.96(\mathrm{~d}, J=11.4 \mathrm{~Hz}, 1 \mathrm{H}), 5.12(\mathrm{~d}, J=11.4 \mathrm{~Hz}, 1 \mathrm{H}), 5.74(\mathrm{dd}, J=9.0 \mathrm{~Hz}, 5.4$ $\mathrm{Hz}, 1 \mathrm{H}), 6.17$ (dd, $J=17.4 \mathrm{~Hz}, 11.4 \mathrm{~Hz}, 1 \mathrm{H}) ;{ }^{13} \mathrm{C} \mathrm{NMR}\left(150 \mathrm{MHz}, \mathrm{CDCl}_{3}\right.$ ) $\delta: 12.2$ (q), 21.7 (q), 22.2 (t), 31.1 (d), 36.7 (t), 38.1 (d), 40.5 (d), 80.5 (d), 111.9 (t), 127.1 (d), 139.8 (d), 144.2 (s), 179.6 (s); IR (KBr): 2933, $1743 \mathrm{~cm}^{-1}$; MS (EI) m/z: $206\left(\mathrm{M}^{+}\right), 91$ (100\%); HRMS (EI) calcd for $\mathrm{C}_{13} \mathrm{H}_{18} \mathrm{O}_{2}$ : 206.1307, found: 206.1311.

\subsection{Synthesis of (+)-8-epi-xanthatin (1)}

4.4.1. (3R,3aS,7S,8aR)-3-Bromo-3,7-dimethyl-6-vinyl-3,3a,4,7,8,8a-hexahydro-2H-cyclohepta [b]furan-2-one 51. To a solution of 5 (70.0 $\mathrm{mg}, 0.34 \mathrm{mmol})$ in THF $(3.4 \mathrm{~mL})$ was added LDA (0.61 M) $(0.72 \mathrm{~mL}, 0.44 \mathrm{mmol})$ at $-78{ }^{\circ} \mathrm{C}$. The mixture was stirred for $1 \mathrm{~h}$ at $-78{ }^{\circ} \mathrm{C}$, and then $\mathrm{CBr}_{4}(225$ $\mathrm{mg}, 0.68 \mathrm{mmol})$ in THF $(1.0 \mathrm{~mL})$ was added dropwise at $-78{ }^{\circ} \mathrm{C}$. After $20 \mathrm{~min}$ at $-78{ }^{\circ} \mathrm{C}$, the reaction was quenched with aqueous saturated $\mathrm{NH}_{4} \mathrm{Cl}$, and the mixture was extracted with $\mathrm{CH}_{2} \mathrm{Cl}_{2}$. The combined organic layers were washed with brine, and dried over $\mathrm{MgSO}_{4}$. After the mixture was evaporated, the residue was purified by silica gel column chromatography ( $5 \% \mathrm{EtOAc} / \mathrm{Hex})$ to give $\mathbf{5 1}(37.4 \mathrm{mg}, 39 \%)$ as a colorless oil and $\mathbf{5 2}(53 \%)$ as a white solid.

51: $[\alpha]_{\mathrm{D}}{ }^{25}-44.4\left(c\right.$ 0.27, $\left.\mathrm{CHCl}_{3}\right) ;{ }^{1} \mathrm{H}-\mathrm{NMR}\left(600 \mathrm{MHz}, \mathrm{CDCl}_{3}\right) \delta: 1.19(\mathrm{~d}, J=7.2 \mathrm{~Hz}, 3 \mathrm{H}), 1.87$ (s, $3 \mathrm{H}), 2.00-2.06(\mathrm{~m}, 1 \mathrm{H}), 2.15-2.24(\mathrm{~m}, 2 \mathrm{H}), 2.37-2.42(\mathrm{~m}, 1 \mathrm{H}), 2.67-2.73(\mathrm{~m}, 1 \mathrm{H}), 3.10$ (ddd, $J=$ 13.2 Hz, 7.2 Hz, 3.0 Hz, 1H), 4.94 (ddd, $J=11.4 \mathrm{~Hz}, 6.6 \mathrm{~Hz}, 4.8 \mathrm{~Hz}, 1 \mathrm{H}), 4.99$ (d, $J=10.8 \mathrm{~Hz}, 1 \mathrm{H})$, $5.13(\mathrm{~d}, J=18.0 \mathrm{~Hz}, 1 \mathrm{H}), 5.73(\mathrm{dd}, J=9.0 \mathrm{~Hz}, 4.2 \mathrm{~Hz}, 1 \mathrm{H}), 6.17(\mathrm{dd}, J=18.0 \mathrm{~Hz}, 10.8 \mathrm{~Hz}, 1 \mathrm{H}) ;{ }^{13} \mathrm{C}$

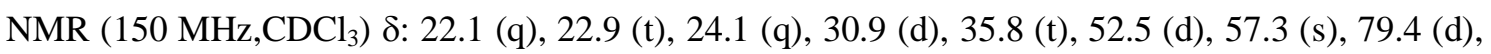
112.8 (t), 125.2 (d), 139.6 (d), 145.2 (s), 174.3 (s); IR $\left(\mathrm{CHCl}_{3}\right): 2958,1774,1207 \mathrm{~cm}^{-1} ; \mathrm{MS}(\mathrm{EI}) \mathrm{m} / \mathrm{z}$ : $286\left([\mathrm{M}+\mathrm{H}]^{+}\right), 284\left([\mathrm{M}-1]^{+}\right), 79(100 \%)$; HRMS (EI) calcd for $\mathrm{C}_{13} \mathrm{H}_{17} \mathrm{O}_{2} \mathrm{Br}$ : 284.0412, found: 284.0411. 
52: mp 86-87.5 ${ }^{\circ} \mathrm{C} ;[\alpha]_{\mathrm{D}}{ }^{25}-16.7\left(c \mathrm{c} 0.18, \mathrm{CHCl}_{3}\right) ;{ }^{1} \mathrm{H}-\mathrm{NMR}\left(600 \mathrm{MHz}, \mathrm{CDCl}_{3}\right) \delta: 1.19(\mathrm{~d}, J=6.6 \mathrm{~Hz}$, 3H), 1.93 (s, 3H), 2.16 (ddd, $J=14.4 \mathrm{~Hz}, 7.8 \mathrm{~Hz}, 1.8 \mathrm{~Hz}, 1 \mathrm{H}$ ), 2.25 (ddd, $J=13.8 \mathrm{~Hz}, 9.0 \mathrm{~Hz}, 4.8$ $\mathrm{Hz}, 1 \mathrm{H}), 2.43-2.49$ (m, 2H), 2.79-2.88 (m, 2H), 4.51 (ddd, $J=12.6 \mathrm{~Hz}, 8.4 \mathrm{~Hz}, 1.8 \mathrm{~Hz}, 1 \mathrm{H}), 5.00(\mathrm{~d}$, $J=10.8 \mathrm{~Hz}, 1 \mathrm{H}), 5.15(\mathrm{~d}, J=17.4 \mathrm{~Hz}, 1 \mathrm{H}), 5.74(\mathrm{dd}, J=9.0 \mathrm{~Hz}, 6.0 \mathrm{~Hz}, 1 \mathrm{H}), 6.16$ (dd, $J=17.4 \mathrm{~Hz}$, $10.8 \mathrm{~Hz}, 1 \mathrm{H}) ;{ }^{13} \mathrm{C} \mathrm{NMR}\left(150 \mathrm{MHz}, \mathrm{CDCl}_{3}\right) \delta: 21.2$ (q), 25.9 (t), 27.8 (q), $31.2(\mathrm{~d}), 33.0$ (t), 47.1 (d), 58.5 (s), 79.1 (d), 112.0 (t), 125.5 (d), 139.6 (d), 143.9 (s), 174.8 (s); IR $\left(\mathrm{CHCl}_{3}\right): 2941,1762,1236$, 1209, 1105, $979 \mathrm{~cm}^{-1}$; MS (EI) m/z: $286\left([\mathrm{M}+\mathrm{H}]^{+}\right), 284$ ([M-1] $\left.]^{+}\right), 91$ (100\%); HRMS (EI) calcd for $\mathrm{C}_{13} \mathrm{H}_{17} \mathrm{O}_{2} \mathrm{Br}: 284.0412$, found: 284.0417.

Conversion of $\mathbf{5 2}$ to 51: To a solution of $\mathbf{5 2}(7.7 \mathrm{mg}, 27.0 \mu \mathrm{mol})$ in THF $(300 \mu \mathrm{L})$ was added LDA $(0.61 \mathrm{M}, 66 \mu \mathrm{L}, 40.5 \mu \mathrm{mol})$ at $-78{ }^{\circ} \mathrm{C}$. The mixture was stirred for $1 \mathrm{~h}$ at $-78{ }^{\circ} \mathrm{C}$, then $\mathrm{CBr}_{4}(17.9 \mathrm{mg}$, $54 \mu \mathrm{mol})$ in THF $(200 \mu \mathrm{L})$ was added dropwise at $-78{ }^{\circ} \mathrm{C}$. After $20 \mathrm{~min}$ at $-78{ }^{\circ} \mathrm{C}$, the reaction was quenched with aqueous saturated $\mathrm{NH}_{4} \mathrm{Cl}$, and the mixture was extracted with $\mathrm{CH}_{2} \mathrm{Cl}_{2}$. The combined organic layers were washed with brine, then dried over $\mathrm{MgSO}_{4}$. After the mixture was evaporated, the residue was purified by silica gel column chromatography (5\% EtOAc/Hex) to give $\mathbf{5 1}$ (3.3 $\mathrm{mg}$, $43 \%)$ as a colorless oil and $\mathbf{5 2}(4.4 \mathrm{mg}, \mathbf{5 7 \%})$ as a white solid.

4.4.2. $\quad(3 \mathrm{a} R, 7 S, 8 \mathrm{a} R)$-7-methyl-3-methylene-6-vinyl-3,3a,4,7,8,8a-hexahydro-2H-cyclohepta[ $b$ ] furan-2-one 53. To a solution of $\mathbf{5 1}(3.9 \mathrm{mg}, 13.7 \mu \mathrm{mol})$ in THF $(0.35 \mathrm{~mL})$ was added TBAF (1.0 M, $27.4 \mu \mathrm{l}, 27.4 \mu \mathrm{mol}$ ) at room temperature. The reaction was stirred for $30 \mathrm{~min}$ at room temperature before the reaction was quenched with aqueous saturated $\mathrm{NH}_{4} \mathrm{Cl}$. The mixture was extracted with $\mathrm{CH}_{2} \mathrm{Cl}_{2}$, and the combined organic layers were washed with brine, and dried over $\mathrm{MgSO}_{4}$. After the mixture was evaporated, the residue was purified by silica gel column chromatography $(10 \%$ AcOEt/Hex) to give $\mathbf{5 3}(2.8 \mathrm{mg})$ as colorless needles: $\mathrm{mp} 74.5-75.5^{\circ} \mathrm{C}($ EtOAc-Hex $)$; $[\alpha]_{\mathrm{D}}{ }^{25}+14.8$ (c 0.27, $\mathrm{CHCl}_{3}$ ); ${ }^{1} \mathrm{H}-\mathrm{NMR}\left(600 \mathrm{MHz}, \mathrm{CDCl}_{3}\right) \delta: 1.18(\mathrm{~d}, J=6.6 \mathrm{~Hz}, 3 \mathrm{H}), 1.84-1.90(\mathrm{~m}, 1 \mathrm{H}), 2.13$ (ddd, $J=13.8 \mathrm{~Hz}, 7.2 \mathrm{~Hz}, 2.4 \mathrm{~Hz}, 1 \mathrm{H}$ ), 2.37 (ddd, $J=13.8 \mathrm{~Hz}, 8.4 \mathrm{~Hz}, 4.8 \mathrm{~Hz}, 1 \mathrm{H}$ ), 2.51 (ddd, $J=$ $13.8 \mathrm{~Hz}, 13.8 \mathrm{~Hz}, 6.0 \mathrm{~Hz}, 1 \mathrm{H}), 2.80-2.87(\mathrm{~m}, 1 \mathrm{H}), 3.36-3.42(\mathrm{~m}, 1 \mathrm{H}), 4.66$ (ddd, $J_{l}=12.0 \mathrm{~Hz}, 8.4$ $\mathrm{Hz}, 2.4 \mathrm{~Hz}, 1 \mathrm{H}), 5.00(\mathrm{~d}, J=11.4 \mathrm{~Hz}, 1 \mathrm{H}), 5.14(\mathrm{~d}, J=17.4 \mathrm{~Hz}, 1 \mathrm{H}), 5.54(\mathrm{~d}, J=3.0 \mathrm{~Hz}, 1 \mathrm{H}), 5.77$ (dd, $J=9.0 \mathrm{~Hz}, 6.6 \mathrm{~Hz}, 1 \mathrm{H}), 6.16(\mathrm{dd}, J=17.4 \mathrm{~Hz}, 11.4 \mathrm{~Hz}, 1 \mathrm{H}), 6.29(\mathrm{~d}, 1 \mathrm{H}, J=3.0 \mathrm{~Hz}) ;{ }^{13} \mathrm{C} \mathrm{NMR}$

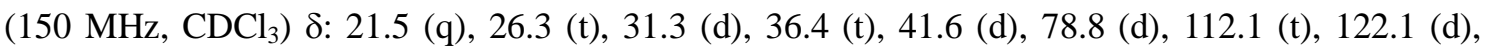
126.4 (s), 138.6 (d), 139.6 (d), 143.9 (s), 170.2 (s); IR ( $\left.\mathrm{CHCl}_{3}\right): 2931,1747,1272,977 \mathrm{~cm}^{-1}$; MS (EI) m/z: $204\left(\mathrm{M}^{+}\right), 93$ (100\%); HRMS (EI) calcd for $\mathrm{C}_{13} \mathrm{H}_{16} \mathrm{O}_{2}$ : 204.1150, found: 204.1153.

4.4.3. (+)-8-epi-Xanthatine 1. To a solution of $\mathbf{5 3}(1.7 \mathrm{mg}, 8.3 \mu \mathrm{mol})$ in dry $\mathrm{CH}_{2} \mathrm{Cl}_{2}(1.5 \mathrm{~mL})$, the $2^{\text {nd }}$ generation Hoveyda-Grubbs catalyst $54(0.5 \mathrm{mg}, 0.83 \mu \mathrm{mol})$ was added. Freshly distilled methyl vinyl ketone ( $13.4 \mu \mathrm{l}, 166.4 \mu \mathrm{mol})$ was added to the mixture using a syringe pump over $8 \mathrm{~h}$ at $45^{\circ} \mathrm{C}$. Upon completion, the mixture was cooled to room temperature before DMSO $(15.0 \mu \mathrm{l})$ was added. 
After $6 \mathrm{~h}$ at room temperature, the mixture was evaporated, and the residue was purified by silica gel column chromatography (30\% EtOAc/Hex) to give 8-epi-xanthatin (1) $(1.7 \mathrm{mg}, 85 \%)$ as a colorless oil. $[\alpha]_{\mathrm{D}}{ }^{23}+44.0\left(\right.$ c $\left.0.25, \mathrm{CHCl}_{3}\right) ;{ }^{1} \mathrm{H}-\mathrm{NMR}\left(600 \mathrm{MHz}, \mathrm{CDCl}_{3}\right) \delta: 1.18(\mathrm{~d}, J=6.6 \mathrm{~Hz}, 3 \mathrm{H}), 1.88-1.94$ (m, 1H), 2.17 (ddd, $J=13.8 \mathrm{~Hz}, 7.2 \mathrm{~Hz}, 2.4 \mathrm{~Hz}, 1 \mathrm{H}$ ), 2.30 (s, 3H), 2.57-2.65 (m, 1H), 2.50 (ddd, $J=$ $13.8 \mathrm{~Hz}, 9.0 \mathrm{~Hz}, 4.8 \mathrm{~Hz}, 1 \mathrm{H}), 2.61$ (ddd, $J=13.8 \mathrm{~Hz}, 13.8 \mathrm{~Hz}, 6.0 \mathrm{~Hz}, 1 \mathrm{H}), 2.80-2.86(\mathrm{~m}, 1 \mathrm{H})$, 3.39-3.44 (m, 1H), 4.65 (ddd, $J=12.0 \mathrm{~Hz}, 8.4 \mathrm{~Hz}, 2.4 \mathrm{~Hz}, 1 \mathrm{H}), 5.57$ (d, $J=2.4 \mathrm{~Hz}, 1 \mathrm{H}), 6.13$ (d, $J=$ $16.2 \mathrm{~Hz}, 1 \mathrm{H}), 6.20(\mathrm{dd}, J=9.0 \mathrm{~Hz}, 6.0 \mathrm{~Hz}, 1 \mathrm{H}), 6.32$ (d, $J=3.6 \mathrm{~Hz}, 1 \mathrm{H}), 6.97$ (d, $J=16.2 \mathrm{~Hz}, 1 \mathrm{H})$; ${ }^{13} \mathrm{C}$ NMR (150 MHz, $\mathrm{CDCl}_{3}$ ) $\delta: 21.5$ (q), 27.0 (q), 27.7 (d), 31.7 (q), 36.3 (t), 41.1 (d), 78.2 (d), $122.5(\mathrm{t}), 125.8$ (d), 135.7 (d), 138.1 (s), 142.9 (s), 146.4 (d), 169.8 (s), 198.5 (s); IR $\left(\mathrm{CHCl}_{3}\right): 3018$, 1758, 1668, 1593, 1274, $1207 \mathrm{~cm}^{-1}$; MS (FAB) m/z: $247\left([\mathrm{M}+\mathrm{H}]^{+}\right)$; HRMS (FAB) calcd for $\mathrm{C}_{15} \mathrm{H}_{19} \mathrm{O}_{3}\left([\mathrm{M}+\mathrm{H}]^{+}\right): 247.1334$, found: 247.1337 .

\subsection{Synthesis of (-)-dihydroxanthatin (2)}

4.5.1. ( $S$ )- $N, N$-Diethyl-2-((1R,5S,7R)-7-hydroxy-5-methyl-4-vinylcyclohept-3-enyl)propanamide 57. To a solution of $5(20.0 \mathrm{mg}, 97.9 \mu \mathrm{mol})$ in $\mathrm{CH}_{2} \mathrm{Cl}_{2}(1.0 \mathrm{~mL})$ were added $\mathrm{AlCl}_{3}(39.1 \mathrm{mg}, 293.7$ $\mu \mathrm{mol})$ and $\mathrm{Et}_{2} \mathrm{NH}(30.6 \mathrm{~mL}, 293.7 \mu \mathrm{mol})$ at room temperature. After $30 \mathrm{~min}$ at room temperature, the reaction was quenched with $1 \mathrm{M} \mathrm{HCl}$, whereupon the mixture was extracted with $\mathrm{CH}_{2} \mathrm{Cl}_{2}$. The combined organic layers were washed with saturated aqueous $\mathrm{NaHCO}_{3}$ and brine, and dried over $\mathrm{MgSO}_{4}$. After the mixture was evaporated, the residue was purified by silica gel column chromatography $(50 \% \mathrm{AcOEt} / \mathrm{Hex})$ to give $\mathbf{5 7}(27.4 \mathrm{mg})$ as a colorless oil. $[\alpha]_{\mathrm{D}}{ }^{23}-75.0(c 0.40$, $\left.\mathrm{CHCl}_{3}\right) ;{ }^{1} \mathrm{H}-\mathrm{NMR}\left(600 \mathrm{MHz}, \mathrm{CDCl}_{3}\right) \delta: 1.12-1.20(\mathrm{~m}, 6 \mathrm{H}), 1.19(\mathrm{t}, J=7.2 \mathrm{~Hz}, 3 \mathrm{H}), 1.28(\mathrm{~d}, J=7.2$ $\mathrm{Hz}, 3 \mathrm{H}), 1.72$ (dd, $J=15.0 \mathrm{~Hz}, 9.0 \mathrm{~Hz}, 1 \mathrm{H}), 1.82(\mathrm{dt}, J=15.0 \mathrm{~Hz}, 3.6 \mathrm{~Hz}, 1 \mathrm{H}), 1.86(\mathrm{bs}, 1 \mathrm{H})$, 1.93-1.97 (m, 1H), $2.02(\mathrm{dt}, J=15.0 \mathrm{~Hz}, 5.4 \mathrm{~Hz}, 1 \mathrm{H}), 2.61$ (ddd, $J=15.6 \mathrm{~Hz}, 11.4 \mathrm{~Hz}, 4.8 \mathrm{~Hz}, 1 \mathrm{H})$, 2.75-2.84 (m, 2H), 3.30-3.45 (m, 4H), 4.31 (bs, $1 \mathrm{H}), 4.87$ (d, $J=10.8 \mathrm{~Hz}, 1 \mathrm{H}), 5.07$ (d, $J=16.8 \mathrm{~Hz}$, $1 \mathrm{H}), 5.78(\mathrm{dd}, J=9.0 \mathrm{~Hz}, 4.2 \mathrm{~Hz}, 1 \mathrm{H}), 6.21(\mathrm{dd}, J=16.8 \mathrm{~Hz}, 10.2 \mathrm{~Hz}, 1 \mathrm{H}) ;{ }^{13} \mathrm{C} \mathrm{NMR}(150 \mathrm{MHz}$, $\left.\mathrm{CDCl}_{3}\right) \delta: 13.1(\mathrm{q}), 15.0(\mathrm{q}), 15.9(\mathrm{q}), 19.8(\mathrm{t}), 26.0(\mathrm{t}), 30.6(\mathrm{~d}), 38.2(\mathrm{~d}), 40.0(\mathrm{t}), 40.6(\mathrm{t}), 42.1(\mathrm{t})$, 43.9 (q), 71.5 (d), 109.6 (d), 131.3 (d), 140.5 (d), 145.8 (s), 176.1 (s); IR $\left(\mathrm{CHCl}_{3}\right): 2985,2358,1731$, 1618, 1462, $1434 \mathrm{~cm}^{-1}$; MS (FAB) m/z: $280\left([\mathrm{M}+\mathrm{H}]^{+}\right) ; 280(100 \%)$; HRMS (FAB) calcd for $\mathrm{C}_{17} \mathrm{H}_{30} \mathrm{NO}_{2}\left([\mathrm{M}+\mathrm{H}]^{+}\right): 280.2277$, found: 280.2276 .

4.5.2. (S)-N,N-Diethyl-2-((1R,5S)-5-methyl-7-oxo-4-vinylcyclohept-3-enyl)propanamide 58. To a solution of $57(12.3 \mathrm{mg}, 44.0 \mu \mathrm{mol})$ in $\mathrm{CH}_{2} \mathrm{Cl}_{2}(0.44 \mathrm{~mL})$ were added $N$-methylmorpholine oxide (NMO, $25.8 \mathrm{mg}, 0.22 \mathrm{mmol}$ ) and MS4A $(22 \mathrm{mg}$ ) at room temperature. After $10 \mathrm{~min}$ at room temperature, tetrapropylammonium perruthenate (TPAP, $1.5 \mathrm{mg}, 4.4 \mu \mathrm{mol}$ ) was added. After $30 \mathrm{~min}$, the mixture was filtered and concentrated. The residue was purified by silica gel column chromatography (40\% AcOEt/Hex) to give $\mathbf{5 8}(9.9 \mathrm{mg}, 81 \%)$ as a colorless oil. $[\alpha]_{\mathrm{D}}^{23}+44.9(c 0.29$, 
$\left.\mathrm{CHCl}_{3}\right) ;{ }^{1} \mathrm{H}-\mathrm{NMR}\left(600 \mathrm{MHz}, \mathrm{CDCl}_{3}\right) \delta: 1.06(\mathrm{~d}, J=7.2 \mathrm{~Hz}, 3 \mathrm{H}), 1.10(\mathrm{~d}, J=6.6 \mathrm{~Hz}, 3 \mathrm{H}), 1.13(\mathrm{t}, J$ $=7.2 \mathrm{~Hz}, 3 \mathrm{H}), 1.20(\mathrm{t}, J=6.6 \mathrm{~Hz}, 3 \mathrm{H}), 2.06(\mathrm{ddd}, J=16.2 \mathrm{~Hz}, 12.0 \mathrm{~Hz}, 6.6 \mathrm{~Hz}, 1 \mathrm{H}), 2.28(\mathrm{ddd}, J=$ $15.0 \mathrm{~Hz}, 9.6 \mathrm{~Hz}, 3.6 \mathrm{~Hz}, 1 \mathrm{H}), 2.63$ (d, $J=6.0 \mathrm{~Hz}, 2 \mathrm{H}), 2.84$ (ddd, $J=12.6 \mathrm{~Hz}, 10.2 \mathrm{~Hz}, 3.6 \mathrm{~Hz}, 1 \mathrm{H}$ ), 3.00-3.07 (m, 2H), 3.32-3.45 (m, 4H), $4.96(\mathrm{~d}, J=10.8 \mathrm{~Hz}, 1 \mathrm{H}), 5.13(\mathrm{~d}, J=17.4 \mathrm{~Hz}, 1 \mathrm{H}), 5.83(\mathrm{dd}$, $J=9.0 \mathrm{~Hz}, 4.8 \mathrm{~Hz}, 1 \mathrm{H}), 6.23(\mathrm{dd}, J=17.4 \mathrm{~Hz}, 10.8 \mathrm{~Hz}, 1 \mathrm{H}) ;{ }^{13} \mathrm{C} \mathrm{NMR}\left(150 \mathrm{MHz}, \mathrm{CDCl}_{3}\right) \delta: 13.2$ (q), $15.1(\mathrm{q}), 17.2(\mathrm{~d}), 18.4(\mathrm{t}), 27.9(\mathrm{t}), 29.8$ (d), $36.4(\mathrm{~d}), 40.6(\mathrm{t}), 42.2(\mathrm{t}), 49.1(\mathrm{t}), 56.2(\mathrm{~d}), 111.0$ (t), 129.7 (d), 140.2 (d), 145.0 (q), 174.2 (q), 212.3 (q); IR $\left(\mathrm{CHCl}_{3}\right):$ 2975, 1701, 1627, 1463, 1220 $\mathrm{cm}^{-1}$; MS (FAB) m/z: $278\left([\mathrm{M}+\mathrm{H}]^{+}\right)$; HRMS (FAB) calcd for $\mathrm{C}_{17} \mathrm{H}_{28} \mathrm{NO}_{2}\left([\mathrm{M}+\mathrm{H}]^{+}\right): 278.2120$, found: 278.2117.

4.5.3. ( $S)$ - $N, N$-Diethyl-2-((1R,5S,7S)-7-hydroxy-5-methyl-4-vinylcyclohept-3-enyl)propanamide $\mathbf{5 9 .}$ To a solution of $58(2.0 \mathrm{mg}, 7.2 \mu \mathrm{mol})$ in THF $(0.8 \mathrm{~mL})$ were added $\mathrm{Et}_{3} \mathrm{~N}(5.0 \mu \mathrm{L}, 36 \mu \mathrm{mol}), \mathrm{H}_{2} \mathrm{O}(1$ $\mu \mathrm{L}, 45 \mu \mathrm{mol})$ and $\mathrm{SmI}_{2}(0.1 \mathrm{M}$ in THF, $180 \mu \mathrm{l}, 18.0 \mu \mathrm{mol})$ at $0{ }^{\circ} \mathrm{C}$. The mixture was stirred for a few seconds at $0{ }^{\circ} \mathrm{C}$, whereupon the reaction was quenched with saturated aqueous $\mathrm{NH}_{4} \mathrm{Cl}$, and then extracted with EtOAc. The combined organic layers were washed with saturated aqueous $\mathrm{NaHCO}_{3}$ and brine, and dried over $\mathrm{MgSO}_{4}$. After the mixture was evaporated, the residue was purified by silica gel column chromatography (50\% AcOEt/Hex) to give $\mathbf{5 9}(1.6 \mathrm{mg}, 80 \%)$ and the $\mathrm{C} 8$-isomer $(20 \%)$ as colorless oils. Major isomer 59: $[\alpha]_{\mathrm{D}}{ }^{23}-80.0\left(c 0.25, \mathrm{CHCl}_{3}\right) ;{ }^{1} \mathrm{H}-\mathrm{NMR}\left(600 \mathrm{MHz}, \mathrm{CDCl}_{3}\right)$ $\delta: 1.11-1.23(\mathrm{~m}, 6 \mathrm{H}), 1.21(\mathrm{t}, J=7.2 \mathrm{~Hz}, 3 \mathrm{H}), 1.27(\mathrm{~d}, J=7.2 \mathrm{~Hz}, 3 \mathrm{H}), 1.59-1.69(\mathrm{~m}, 2 \mathrm{H}), 2.00-2.38$ (m, 1H), 2.40 (ddd, $J=16.2 \mathrm{~Hz}, 12.0 \mathrm{~Hz}, 4.8 \mathrm{~Hz}, 1 \mathrm{H}$ ), 2.78 (ddd, $J=14.4 \mathrm{~Hz}, 7.2 \mathrm{~Hz}, 2.4 \mathrm{~Hz}, 1 \mathrm{H}$ ), 2.87-2.92 (m, 1H), 3.28-3.36 (m, 2H), 3.39-3.399 (m, 2H), 3.95-3.99 (m, 1H), 4.92 (d, J = 10.8 Hz, $1 \mathrm{H}), 5.15(\mathrm{~d}, J=17.4 \mathrm{~Hz}, 1 \mathrm{H}), 5.16(\mathrm{~s}, 1 \mathrm{H}), 5.72(\mathrm{dd}, J=9.6 \mathrm{~Hz}, 4.8 \mathrm{~Hz}, 1 \mathrm{H}), 6.21$ (dd, $J=17.4 \mathrm{~Hz}$, $10.8 \mathrm{~Hz}, 1 \mathrm{H}) ;{ }^{13} \mathrm{C} \mathrm{NMR}\left(150 \mathrm{MHz}, \mathrm{CDCl}_{3}\right) \delta: 12.7$ (q), 13.0 (q), 14.9 (q), 17.1 (q), 28.6 (d), 31.1 (t), $40.9(\mathrm{t}), 41.5(\mathrm{~d}), 42.0(\mathrm{t}), 42.5(\mathrm{t}), 46.5(\mathrm{~d}), 69.5(\mathrm{~d}), 110.2(\mathrm{t}), 129.3(\mathrm{~d}), 140.1(\mathrm{~d}), 146.7(\mathrm{~s}), 177.1$ (s); IR $\left(\mathrm{CHCl}_{3}\right)$ : 2974, 2933, 1608, $1456 \mathrm{~cm}^{-1}$; MS (FAB) m/z: $280\left([\mathrm{M}+\mathrm{H}]^{+}\right)$; HRMS (FAB) calcd for $\mathrm{C}_{17} \mathrm{H}_{30} \mathrm{NO}_{2}\left([\mathrm{M}+\mathrm{H}]^{+}\right): 280.2277$, found: 280.2276 .

4.5.4. (3S,3a R,7S,8a $S)$-3,7-Dimethyl-6-vinyl-3,3a,4,7,8,8a-hexahydro-2H-cyclohepta[b]furan-2-one 60. ${ }^{8 \mathrm{c}}$ To a solution of $\mathbf{5 9}(16.5 \mathrm{mg}, 59.1 \mu \mathrm{mol})$ in THF $(0.47 \mathrm{~mL})$ was added $3 \mathrm{M} \mathrm{HCl}(0.11 \mathrm{~mL})$. The mixture was refluxed for $30 \mathrm{~min}$. The reaction was quenched with saturated aqueous $\mathrm{NaHCO}_{3}$, and extracted with $\mathrm{Et}_{2} \mathrm{O}$. The combined organic layers were washed with brine, and dried over $\mathrm{MgSO}_{4}$. After the mixture was evaporated, the residue was purified by silica gel column chromatography (10\% AcOEt/Hex) to give $\mathbf{6 0}(10.5 \mathrm{mg}, 86 \%)$ as colorless prisms. $\mathrm{mp} 82.5-83.5^{\circ} \mathrm{C}$; $[\alpha]_{\mathrm{D}}{ }^{23}-103.1\left(c 0.32, \mathrm{CHCl}_{3}\right) ;{ }^{1} \mathrm{H}-\mathrm{NMR}\left(600 \mathrm{MHz}, \mathrm{CDCl}_{3}\right) \delta: 1.13(\mathrm{~d}, J=7.8 \mathrm{~Hz}, 3 \mathrm{H}), 1.22(\mathrm{~d}, J=$ $7.8 \mathrm{~Hz}, 3 \mathrm{H}), 1.70$ (ddd, $J=12.6 \mathrm{~Hz}, 12.6 \mathrm{~Hz}, 3.6 \mathrm{~Hz}, 1 \mathrm{H}), 2.07-2.16(\mathrm{~m}, 2 \mathrm{H}), 2.28-2.34(\mathrm{~m}, 2 \mathrm{H})$, $2.69(\mathrm{dq}, J=7.8 \mathrm{~Hz}, 7.8 \mathrm{~Hz}, 1 \mathrm{H}), 3.07$ (ddq, $J=7.8 \mathrm{~Hz}, 4.2 \mathrm{~Hz}, 4.2 \mathrm{~Hz}, 1 \mathrm{H}), 4.53$ (ddd, $J=12.6 \mathrm{~Hz}$, 
$10.2 \mathrm{~Hz}, 3.0 \mathrm{~Hz}, 1 \mathrm{H}), 4.96(\mathrm{~d}, J=10.8 \mathrm{~Hz}, 1 \mathrm{H}), 5.17(\mathrm{~d}, J=17.4 \mathrm{~Hz}, 1 \mathrm{H}), 5.81(\mathrm{dd}, J=9.6 \mathrm{~Hz}, 3.6$ $\mathrm{Hz}, 1 \mathrm{H}), 6.23(\mathrm{dd}, J=17.4 \mathrm{~Hz}, 10.8 \mathrm{~Hz}, 1 \mathrm{H}) ;{ }^{13} \mathrm{C} \mathrm{NMR}\left(150 \mathrm{MHz}, \mathrm{CDCl}_{3}\right) \delta: 10.2$ (q), 18.4 (q),25.0 (t), 28.1 (d), 36.5 (t), 40.0 (d), 46.2 (d), 81.4 (d), 110.3 (t), 129.8 (d), 141.4 (d), 145.4 (s), 180.0 (s); IR (KBr): 2958, 2929, 1766, 1627, 1465, 1450, 1211, 1039, 989, $887 \mathrm{~cm}^{-1}$; MS (EI) m/z: $206\left(\mathrm{M}^{+}\right)$, 79 (100\%); HRMS (EI) calcd for $\mathrm{C}_{13} \mathrm{H}_{18} \mathrm{O}_{2}: 206.1307$, found: 206.1302.

4.5.5. (-)-Dihydroxanthatin $2 .{ }^{8 \mathrm{c}}$ To a solution of $\mathbf{6 0}(6.2 \mathrm{mg}, 30 \mu \mathrm{mol})$ in dry $\mathrm{CH}_{2} \mathrm{Cl}_{2}(6.0 \mathrm{~mL})$ were added the 2nd generation Hoveyda-Grubbs catalyst $54(1.9 \mathrm{mg}, 3.0 \mu \mathrm{mol})$, and freshly distilled methyl vinyl ketone ( $49 \mu \mathrm{L}, 0.60 \mathrm{mmol})$. The mixture was stirred at $45^{\circ} \mathrm{C}$ for $1 \mathrm{~h}$. Upon completion, the mixture was evaporated, and the residue was purified by column chromatography $(30 \%$ EtOAc/Hex) to give dihydroxanthatin (2) $(6.6 \mathrm{mg}, 89 \%)$ as colorless prisms. $\mathrm{mp} 121.0-124.0{ }^{\circ} \mathrm{C}$ $\left(\mathrm{CH}_{2} \mathrm{Cl}_{2}\right.$-hexane); $[\alpha]_{\mathrm{D}}{ }^{23}-75.0$ (c $\left.0.32, \mathrm{CHCl}_{3}\right) ;{ }^{1} \mathrm{H}$ NMR $\left(\mathrm{CDCl}_{3}, 600 \mathrm{MHz}\right) \delta: 1.15$ (d, $J=7.8 \mathrm{~Hz}$, $3 \mathrm{H}), 1.23(\mathrm{~d}, J=7.8 \mathrm{~Hz}, 3 \mathrm{H}), 1.72(\mathrm{ddd}, J=12.6 \mathrm{~Hz}, 12.6 \mathrm{~Hz}, 3.6 \mathrm{~Hz}, 1 \mathrm{H}), 2.13$ (dddd, $12.6 \mathrm{H}, 12.6$ $\mathrm{Hz}, 7.8 \mathrm{~Hz}, 2.4 \mathrm{~Hz}, 1 \mathrm{H}), 2.21$ (ddd, $12.0 \mathrm{H}, 12.0 \mathrm{~Hz}, 3.0 \mathrm{~Hz}, 1 \mathrm{H}$ ), 2.30 (s, 3H), 2.35 (ddd, $J=12.6$ $\mathrm{Hz}, 4.2 \mathrm{~Hz}, 4.2 \mathrm{~Hz}, 1 \mathrm{H}), 2.45$ (ddd, $J=16.2 \mathrm{~Hz}, 9.0 \mathrm{~Hz}, 2.4 \mathrm{~Hz}, 1 \mathrm{H}$ ), 2.72 (dq, $J=7.8 \mathrm{~Hz}, 7.8 \mathrm{~Hz}$, 1H), 3.05 (ddq, $J=7.8 \mathrm{~Hz}, 4.2 \mathrm{~Hz}, 4.2 \mathrm{~Hz}, 1 \mathrm{H}$ ), 4.54 (ddd, $J=12.6 \mathrm{~Hz}, 10.8 \mathrm{~Hz}, 3.0 \mathrm{~Hz}, 1 \mathrm{H}$ ), 6.18 $(\mathrm{d}, J=16.2 \mathrm{~Hz} \mathrm{~Hz}, 1 \mathrm{H}), 6.25$ (dd, $J=9.6 \mathrm{~Hz}, 3.0 \mathrm{~Hz}, 1 \mathrm{H}), 7.05(\mathrm{~d}, J=16.2 \mathrm{~Hz}, 1 \mathrm{H}) ;{ }^{13} \mathrm{C} \mathrm{NMR}$

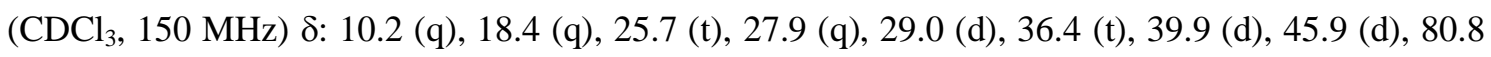
(d), 124.4 (d), 139.3 (d), 144.5 (s), 148.4 (d), 179.0 (s), 198.6 (s); IR (KBr): 2968, 1768, 1679, 1585 , 1357, 1282, 1205, 1180, $981 \mathrm{~cm}^{-1}$; MS (EI) m/z: $248\left(\mathrm{M}^{+}\right), 248$ (100\%); HRMS (EI) calcd for $\mathrm{C}_{15} \mathrm{H}_{20} \mathrm{O}_{3}: 248.1412$, found: 248.1417.

\subsection{Synthesis of (-)-xanthatin (3)}

4.6.1. $N, N$-Diethyl-2-((1R,5S,7R)-7-hydroxy-5-methyl-4-vinylcyclohept-3-enyl)acrylamide 63. To a solution of $\mathbf{5 3}(6.4 \mathrm{mg}, 31.3 \mu \mathrm{mol})$ in $\mathrm{CH}_{2} \mathrm{Cl}_{2}(0.5 \mathrm{~mL})$ were added $\mathrm{AlCl}_{3}(8.4 \mathrm{mg}, 62.7 \mu \mathrm{mol})$ and $\mathrm{Et}_{2} \mathrm{NH}(6.5 \mu \mathrm{l}, 62.7 \mu \mathrm{mol})$ at $0{ }^{\circ} \mathrm{C}$. The mixture was stirred for $30 \mathrm{~min}$ at $\mathrm{RT}$, whereupon the reaction was quenched with $1 \mathrm{M} \mathrm{HCl}$, and the mixture was extracted with $\mathrm{CH}_{2} \mathrm{Cl}_{2}$. The combined organic layers were washed with saturated aqueous $\mathrm{NaHCO}_{3}$ and brine, and dried over $\mathrm{MgSO}_{4}$. After the mixture was evaporated, the residue was purified by silica gel column chromatography $(50 \%$ AcOEt/Hex) to give $\mathbf{6 3}(8.4 \mathrm{mg}, 97 \%)$ as a colorless oil. $[\alpha]_{\mathrm{D}}{ }^{20}-58.3\left(c 0.06, \mathrm{CHCl}_{3}\right) ;{ }^{1} \mathrm{H}-\mathrm{NMR}(600$ $\mathrm{MHz}, \mathrm{CDCl}_{3}$ ) $\delta: 1.18(\mathrm{t}, J=7.2 \mathrm{~Hz}, 6 \mathrm{H}), 1.25(\mathrm{~d}, J=7.2 \mathrm{~Hz}, 3 \mathrm{H}), 1.78$ (ddd, $J=14.4 \mathrm{~Hz}, 4.8 \mathrm{~Hz}$, $2.4 \mathrm{~Hz}, 1 \mathrm{H}), 1.86$ (ddd, $J=14.4 \mathrm{~Hz}, 9.6 \mathrm{~Hz}, 2.4 \mathrm{~Hz}, 1 \mathrm{H}), 2.07$ (ddd, $J=14.4 \mathrm{~Hz}, 7.2 \mathrm{~Hz}, 7.2 \mathrm{~Hz}$, $1 \mathrm{H}), 2.68$ (bd, $J=12.0 \mathrm{~Hz}, 6 \mathrm{H}), 2.78(\mathrm{ddd}, J=14.4 \mathrm{~Hz}, 14.4 \mathrm{~Hz}, 4.2 \mathrm{~Hz}, 1 \mathrm{H}), 2.83$ (dq, $J=7.2 \mathrm{~Hz}$, $7.2 \mathrm{~Hz}, 1 \mathrm{H}), 3.339$ (dq, $J=14.4 \mathrm{~Hz}, 7.2 \mathrm{~Hz}, 1 \mathrm{H}), 3.343$ (dq, $J=14.4 \mathrm{~Hz}, 7.2 \mathrm{~Hz}, 1 \mathrm{H}), 3.55$ (dq, $J=$ 14.4 Hz, 7.2 Hz, 2H), 4.15-4.17 (m, 1H), 4.91 (d, $J=10.8 \mathrm{~Hz}, 1 \mathrm{H}), 4.96$ (bs, 1H), 5.126 (d, $J=16.8$ Hz, 1H), 5.132 (s, 1H), 5.26 (s, m), 5.73 (dd, $J=9.6 \mathrm{~Hz}, 4.8 \mathrm{~Hz}, 1 \mathrm{H}), 6.21$ (dd, $J=16.8 \mathrm{~Hz}, 10.8 \mathrm{~Hz}$, 
$1 \mathrm{H}) ;{ }^{13} \mathrm{C}$ NMR (150 MHz, $\mathrm{CDCl}_{3}$ ) $\delta: 12.6$ (q), $14.2(\mathrm{q}), 20.3(\mathrm{q}), 25.0(\mathrm{t}), 31.4(\mathrm{~d}), 38.4(\mathrm{t}), 39.0(\mathrm{t})$, $43.3(\mathrm{t}), 48.5(\mathrm{~d}), 74.4(\mathrm{~d}), 110.4(\mathrm{t}), 115.8(\mathrm{t}), 129.0$ (d), 140.4 (d), $146.5(\mathrm{~s}), 146.7$ (s), $172.2(\mathrm{~s}) ;$ IR $\left(\mathrm{CHCl}_{3}\right)$ : 2927, 1596, $1458 \mathrm{~cm}^{-1}$; MS (FAB) m/z: $278\left([\mathrm{M}+\mathrm{H}]^{+}\right)$; HRMS (FAB) calcd for $\mathrm{C}_{17} \mathrm{H}_{28} \mathrm{NO}_{2}$ $\left([\mathrm{M}+\mathrm{H}]^{+}\right): 278.2120$, found: 278.2120 .

4.6.2. $N, N$-Diethyl-2-((1R,5S)-5-methyl-7-oxo-4-vinylcyclohept-3-enyl)acrylamide 64. To a solution of $63(7.1 \mathrm{mg}, 25.6 \mu \mathrm{mol})$ in $\mathrm{CH}_{2} \mathrm{Cl}_{2}(0.3 \mathrm{~mL})$ were added $\mathrm{NMO}(15.0 \mathrm{mg}, 128.0 \mu \mathrm{mol})$ and MS4A $(12.8 \mathrm{mg})$ at room temperature. The mixture was stirred for $10 \mathrm{~min}$, and then TPAP $(0.9 \mathrm{mg}, 2.6$ $\mu \mathrm{mol})$ was added. The mixture was stirred for $30 \mathrm{~min}$. After filtration, the filtrate was purified by silica gel column chromatography $(40 \% \mathrm{AcOEt} / \mathrm{Hex})$ to give $\mathbf{6 4}$ as a colorless oil. $[\alpha]_{\mathrm{D}}{ }^{20}+11.6(c$ 0.17, $\left.\mathrm{CHCl}_{3}\right)$; ${ }^{1} \mathrm{H}-\mathrm{NMR}\left(600 \mathrm{MHz}, \mathrm{CDCl}_{3}\right) \delta: 1.15-1.17$ (m, 9H), 2.43 (ddd, $J=15.6 \mathrm{~Hz}, 9.6 \mathrm{~Hz}, 4.2$ Hz, 1H), 2.61 (dd, $J=10.8 \mathrm{~Hz}, 5.4 \mathrm{~Hz}, 1 \mathrm{H}), 2.75-2.80(\mathrm{~m}, 1 \mathrm{H}), 2.92-3.01(\mathrm{~m}, 2 \mathrm{H}), 3.4$ (bs, 3H), 3.47 (dd, $J=13.2 \mathrm{~Hz}, 4.2 \mathrm{~Hz}, 4.2 \mathrm{~Hz}, 1 \mathrm{H}), 3.52$ (bs, $1 \mathrm{H}), 4.98$ (d, $J=10.8 \mathrm{~Hz}, 1 \mathrm{H}), 5.13$ (d, $J=17.4 \mathrm{~Hz}$, 1H), $5.22(\mathrm{~s}, 1 \mathrm{H}), 5.26(\mathrm{~d}, J=1.2 \mathrm{~Hz}, 1 \mathrm{H}), 5.86(\mathrm{dd}, J=9.6 \mathrm{~Hz}, 4.8 \mathrm{~Hz}, 1 \mathrm{H}), 6.20$ (dd, $J=17.4 \mathrm{~Hz}$, $10.8 \mathrm{~Hz}, 1 \mathrm{H}) ;{ }^{13} \mathrm{C}$ NMR $\left(150 \mathrm{MHz}, \mathrm{CDCl}_{3}\right) \delta: 12.6(\mathrm{q}), 14.2$ (q), $20.0(\mathrm{q}), 27.6$ (t), 31.2 (d), $38.8(\mathrm{~d})$, 43.0 (d), 47.3 (t), 57.1 (d), 111.8 (t), 115.3 (t), 128.4 (d), 139.7 (d), 142.9 (s), 144.6 (s), 170.3 (s), 210.3 (s); IR $\left(\mathrm{CHCl}_{3}\right): 2999,1703,1610,1461 \mathrm{~cm}^{-1}$; MS (FAB) m/z: $276\left([\mathrm{M}+\mathrm{H}]^{+}\right) ;$HRMS (FAB) calcd for $\mathrm{C}_{17} \mathrm{H}_{26} \mathrm{NO}_{2}\left([\mathrm{M}+\mathrm{H}]^{+}\right): 276.1964$, found: 276.1966 .

4.6.3. (3aR,7S,8a $S)$-7-Methyl-3-methylene-6-vinyl-3,3a,4,7,8,8a-hexahydro-2H-cyclohepta[ $b]$ furan-2-one 67. To a solution of $64(4.4 \mathrm{mg}, 16.0 \mu \mathrm{mol})$ in THF $(0.3 \mathrm{~mL})$ at $0{ }^{\circ} \mathrm{C}$ was added DIBAL-H $(18.9 \mu \mathrm{L}, 17.6 \mu \mathrm{mol})$. The resulting mixture was stirred for $0.5 \mathrm{~h}$ at room temperature, then cooled to $0{ }^{\circ} \mathrm{C}$, whereupon water was added. The mixture was filtered and the filtrate was dried over $\mathrm{MgSO}_{4}$. The crude product (a mixture of the diastereomers, $\mathbf{6 5 : 6 3}=1: 1.2$ ) was used directly in the next step. 65: $[\alpha]_{\mathrm{D}}{ }^{20}-141.7\left(c 0.06, \mathrm{CHCl}_{3}\right) ;{ }^{1} \mathrm{H}-\mathrm{NMR}\left(600 \mathrm{MHz}, \mathrm{CDCl}_{3}\right) \delta: 1.12(\mathrm{~d}, J=7.8 \mathrm{~Hz}$, $3 \mathrm{H}), 1.18(\mathrm{t}, J=6.6 \mathrm{~Hz}, 6 \mathrm{H}), 1.59-1.61(\mathrm{~m}, 1 \mathrm{H}), 2.14(\mathrm{ddd}, J=13.2 \mathrm{~Hz}, 4.8 \mathrm{~Hz}, 2.4 \mathrm{~Hz}, 1 \mathrm{H})$, 2.17-2.22 (m, 2H), 2.27-2.33 (m, 1H), 2.93-2.96 (m, 1H), $3.40(\mathrm{dd}, J=15.6 \mathrm{~Hz}, 1 \mathrm{H}), 2.61(\mathrm{dd}, J=$ $10.8 \mathrm{~Hz}, 5.4 \mathrm{~Hz}, 1 \mathrm{H}), 2.75-2.80(\mathrm{~m}, 1 \mathrm{H}), 2.92-3.01(\mathrm{~m}, 2 \mathrm{H}), 3.40(\mathrm{dq}, J=14.4 \mathrm{~Hz}, 7.2 \mathrm{~Hz}, 2 \mathrm{H})$, 3.49-3.57 (m, 2H), 3.9 (bt, $J=10.8 \mathrm{~Hz}, 1 \mathrm{H}), 4.64(\mathrm{~d}, J=3.0 \mathrm{~Hz}, 1 \mathrm{H}), 4.95(\mathrm{~d}, J=10.8 \mathrm{~Hz}, 1 \mathrm{H}), 5.15$ (s, 1H), $5.17(\mathrm{~d}, J=17.4 \mathrm{~Hz}, 1 \mathrm{H}), 5.29(\mathrm{~s}, 1 \mathrm{H}), 5.71(\mathrm{dd}, J=9.6 \mathrm{~Hz}, 4.2 \mathrm{~Hz}, 1 \mathrm{H}), 6.22(\mathrm{dd}, J=17.4$ $\mathrm{Hz}, 10.8 \mathrm{~Hz}, 1 \mathrm{H})$.

To a solution of the diastereomeric mixture $(\mathbf{6 5}$ and $\mathbf{6 3})(16.0 \mu \mathrm{mol})$ in THF $(320 \mu \mathrm{L})$ was added $3 \mathrm{M} \mathrm{HCl}(80 \mu \mathrm{L})$. The mixture was refluxed for $30 \mathrm{~min}$. The reaction was quenched with saturated aqueous $\mathrm{NaHCO}_{3}$, and extracted with $\mathrm{Et}_{2} \mathrm{O}$. The combined organic layers were washed with brine, and dried over $\mathrm{MgSO}_{4}$. After the mixture was evaporated, the residue was purified by silica gel column chromatography (10\% AcOEt/Hex) to give $\mathbf{6 7}$ (1.3 mg, 27\% for 2 steps) and $\mathbf{5 3}$ (33\% for 2 
steps) as colorless needles. 67: $\mathrm{mp} 77.2-77.7^{\circ} \mathrm{C}$ (hexane); $[\alpha]_{\mathrm{D}}{ }^{23}-40.0\left(c \quad 0.05, \mathrm{CHCl}_{3}\right) ;{ }^{1} \mathrm{H}-\mathrm{NMR}$ $\left(600 \mathrm{MHz}, \mathrm{CDCl}_{3}\right) \delta: 1.14(\mathrm{~d}, J=7.8 \mathrm{~Hz}, 3 \mathrm{H}), 1.83$ (ddd, $\left.J=12.6 \mathrm{~Hz}, 12.6 \mathrm{~Hz}, 3.6 \mathrm{~Hz}, 1 \mathrm{H}\right), 2.14$ (ddd, $J=16.2 \mathrm{~Hz}, 11.4 \mathrm{~Hz}, 3.6 \mathrm{~Hz}, 1 \mathrm{H}$ ), 2.35 (ddd, $J=13.2 \mathrm{~Hz}, 4.2 \mathrm{~Hz}, 3.6 \mathrm{~Hz}, 1 \mathrm{H}$ ), 2.51-2.56 (m, 1H), 2.67 (ddd, $J=16.2 \mathrm{~Hz}, 9.0 \mathrm{~Hz}, 2.4 \mathrm{~Hz}, 2 \mathrm{H}), 3.11(\mathrm{dq}, J=3.6 \mathrm{~Hz}, 3.6 \mathrm{~Hz}, 1 \mathrm{H}), 4.29$ (ddq, $J=$ $12.6 \mathrm{~Hz}, 10.2 \mathrm{~Hz}, 2.4 \mathrm{~Hz}, 1 \mathrm{H}), 4.99(\mathrm{~d}, J=11.4 \mathrm{~Hz}, 1 \mathrm{H}), 5.20(\mathrm{~d}, J=17.4 \mathrm{~Hz}, 1 \mathrm{H}), 5.47$ (dd, $J=9.0$ $\mathrm{Hz}, 3.0 \mathrm{~Hz}, 1 \mathrm{H}), 6.18(\mathrm{~d}, J=3.0 \mathrm{~Hz}, 1 \mathrm{H}), 6.26(\mathrm{dd}, J=17.4 \mathrm{~Hz}, 10.8 \mathrm{~Hz}, 1 \mathrm{H}) ;{ }^{13} \mathrm{C}$ NMR $(150 \mathrm{MHz}$,

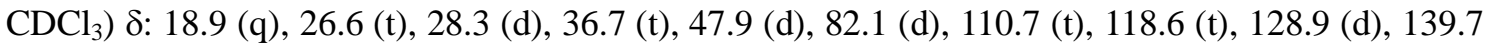
(s), 141.5 (d), 145.7 (s), 170.1 (s); IR $\left(\mathrm{CHCl}_{3}\right)$ : 3005, 1764, $1600 \mathrm{~cm}^{-1}$; MS (EI) m/z: $204\left(\mathrm{M}^{+}\right), 204$ (100\%); HRMS (EI) calcd for $\mathrm{C}_{13} \mathrm{H}_{16} \mathrm{O}_{2}$ : 204.1150, found: 204.1151.

4.6.4. (-)-Xanthatin 3. ${ }^{29}$ To a solution of $67(3.0 \mathrm{mg}, 14.7 \mu \mathrm{mol})$ in dry $\mathrm{CH}_{2} \mathrm{Cl}_{2}(3.0 \mathrm{~mL})$ were added the 2nd generation Hoveyda-Grubbs catalyst $54(0.9 \mathrm{mg}, 1.5 \mu \mathrm{mol})$, and freshly distilled methyl vinyl ketone $(11.9 \mu \mathrm{L}, 147 \mu \mathrm{mol})$. The mixture was stirred at $45{ }^{\circ} \mathrm{C}$ for $1 \mathrm{~h}$. Upon completion, the mixture was evaporated, and the residue was purified by column chromatography (30\% EtOAc/Hex) to give xanthatin (3) (3.0 mg, 83\%) as colorless needles. mp 112.1-113.1 ${ }^{\circ} \mathrm{C}\left(\mathrm{Et}_{2} \mathrm{O}-\right.$ hexane); lit. ${ }^{8 \mathrm{~d}} \mathrm{mp}$ $114.5-115.2{ }^{\circ} \mathrm{C}(\mathrm{EtOH}) ;[\alpha]_{\mathrm{D}}{ }^{25}-20.0\left(c 0.15, \mathrm{CHCl}_{3}\right) ;$ lit. $^{8 \mathrm{~d}}[\alpha]_{\mathrm{D}}-17.8\left(c 0.14, \mathrm{CHCl}_{3}\right) ;{ }^{1} \mathrm{H}-\mathrm{NMR}(600$ $\mathrm{MHz}, \mathrm{CDCl}_{3}$ ) $\delta: 1.17$ (d, $J=7.8 \mathrm{~Hz}, 3 \mathrm{H}$ ), 186 (ddd, $J=12.6 \mathrm{~Hz}, 12.6 \mathrm{~Hz}, 3.6 \mathrm{~Hz}, 1 \mathrm{H}$ ), 2.22 (ddd, $J$ $=12.6 \mathrm{~Hz}, 9.6 \mathrm{~Hz}, 3.6 \mathrm{~Hz}, 1 \mathrm{H}), 2.31(\mathrm{~s}, 3 \mathrm{H}), 2.38(\mathrm{ddd}, J=12.6 \mathrm{~Hz}, 4.2 \mathrm{~Hz}, 2.4 \mathrm{~Hz}, 1 \mathrm{H}), 2.53-2.58$ (m, 1H), 2.80 (ddd, $J=16.2 \mathrm{~Hz}, 8.4 \mathrm{~Hz}, 2.4 \mathrm{~Hz}, 1 \mathrm{H}), 2.80-2.86(\mathrm{~m}, 1 \mathrm{H}), 3.39-3.44(\mathrm{~m}, 1 \mathrm{H}), 4.65$ (ddd, $J=12.0 \mathrm{~Hz}, 8.4 \mathrm{~Hz}, 2.4 \mathrm{~Hz}, 1 \mathrm{H}$ ), 3.09 (ddq, $J=8.4 \mathrm{~Hz}, 4.2 \mathrm{~Hz}, 4.2 \mathrm{~Hz}, 1 \mathrm{H}$ ), 4.30 (ddd, $J=$ $12.6 \mathrm{~Hz}, 9.6 \mathrm{~Hz}, 2.4 \mathrm{~Hz}, 1 \mathrm{H}), 5.49$ (d, $J=3.0 \mathrm{~Hz}, 1 \mathrm{H}), 6.207$ (d, $J=16.2 \mathrm{~Hz}, 1 \mathrm{H}), 6.212$ (d, $J=3.0$ $\mathrm{Hz}, 1 \mathrm{H}), 6.29(\mathrm{dd}, J=9.6 \mathrm{~Hz}, 2.4 \mathrm{~Hz}, 1 \mathrm{H}), 7.08(\mathrm{~d}, J=16.2 \mathrm{~Hz}, 1 \mathrm{H}) ;{ }^{13} \mathrm{C}$ NMR $\left(150 \mathrm{MHz}, \mathrm{CDCl}_{3}\right)$ $\delta: 18.9,27.2,27.9,29.2,36.6,47.5,81.5,119.0,124.7,138.1,139.2,144.8,148.5,169.7,198.5$; IR (KBr): 2927, 1760, 1685, 1587, 1402, 1353, 1247, 1178, 1137, $977 \mathrm{~cm}^{-1}$; MS (EI) m/z: $246\left(\mathrm{M}^{+}\right), 91$ (100\%); HRMS (EI) calcd for $\mathrm{C}_{15} \mathrm{H}_{18} \mathrm{O}_{3}\left(\mathrm{M}^{+}\right)$: 246.1256, found: 246.1258 .

Acknowledgment: This research was partially supported by a Grant-in-Aid for Scientific Research on (B) $(19390007,22390002)$ and the Program for Promotion of Basic and Applied Research for Innovations in the Bio-oriented Industry (BRAIN). K.M. additionally acknowledges the support of the JSPS. We are also grateful to Ms. C. Moriya for experimental contribution in the early stage of this project.

\section{References and notes}

1. (a) Ohno, S.; Tomita-Yokotani, K.; Kosemura, S.; Node, M.; Suzuki, T.; Amano, M.; Yasui, K.; Goto, T.; Yamamura, S.; Hasegawa, K. Phytochemistry 2001, 56, 577-581. (b) Tomita-Yokotani, 
K.; Kato, J.; Kosemura, S.; Yamamura, S.; Kushima, M.; Kakuta, H.; Hasegawa, K. Phytochemistry 1997, 46, 503-506. (c) Yokotani-Domitian, K.; Kato, J.; Yamada, K.; Kosemura, S; Yamamura, S.; Bruinsma, J.; Hasegawa, K. Physiol. Plant. 1999, 106, 326-330.

2. (a) Ahn, J.-W.; No, Z.; Ryu, S.-Y.; Zee, O.-P.; Kim, S.-K. Nat. Prod. Sci. 1995, 1, 1-4. (b) Kovács, A.; Vasas, A.; Forgo, P.; Réthy, B.; Zupkó, I.; Hohmann, J. Zeitschrift für Naturforschung C. A Journal of Biosciences 2009, 64c, 343-349. (c) Ramírez-Erosa, I.; Huang, Y.; Hickie, R. A.; Sutherland, R. G.; Barl, B. Can. J. Physiol. Pharmacol. 2007, 85, 1160-1172. (d) Kim, Y. S.; Kim, J. S.; Park, S.-H. ; Choi, S.-U.; Lee, C. O.; Kim, S.-K.; Kim, Y.-K.; Kim, S. H. Ryu, S. Y. Planta Med. 2003, 69, 375-377.

3. Joshi, S. P.; Rojatkar, S. R.; Nagasampagi, B. A. J. Med. Aromat. Plant Sci. 1997, 19, 366-368.

4. (a) Kato, T.; Yokotani-Tomita, K.; Suzuki, T.; Kosemura, S.; Hasegawa, K. Weed Biol. Manag. 2008, 3, 124-128. (b) Lavault, M.; Landreau, A.; Larcher, G.; Bouchara, J.-P.; Pagniez, F.; Pape, P. L.; Richomme, P. Fitoterapia 2005, 76, 363-366. (c) Ginesta-Peris, E.; Garcia-Breijo, F. J.; Primo-Yúfera, E. Lett. Appl. Microbiol. 1994, 18, 206-208.

5. (a) Little, J. E.; Foote, M. W.; Johnstone, D. B. Arch. Biochem. 1950, 27, 247-254; (b) Geissman, T. A.; Deuel, P.; Bonde, E. K.; Addicott, F. A. J. Am. Chem. Soc. 1954, 76, 685-687; (c) Deuel, P.; Geissman, T. A. J. Am. Chem. Soc. 1957, 79, 3778-3783.

6. Sato, Y.; Oketani, H.; Yamada, T.; Shingyouchi, K.; Ohtsubo, T.; Kihara, M.; Shibata, H.; Higuti, T. J. Pharm. Pharmacol. 1997, 49, 1042-1044.

7. (a) McMillan, C.; Chavez, P. I.; Mabry, T. J. Biochem. Syst. Ecol. 1975, 3, 137-141. (b) Kawazu, K.; Nakajima, S.; Ariwa, M. Experientia 1979, 35, 1294-1295. (c) Bohlmann, F.; Singh, P.; Joshi, K. C.; Singh, C. L. Phytochemistry 1982, 21, 1441-1443. (d) Ghazy, N. M.; Omar, A. A.; Elrashidy, E. M.; Metwally, A. M. Egypt. J. Pharm. Sci. 1988, 29, 39-42. (e) Ahmed, A. A.; Jakupovic, J.; Bohlmann, F.; Regaila, H. A.; Ahmed, A. M. Phytochemistry 1990, 29, 2211-2215. 8. For total syntheses of (+)-8-epi-xanthatin, see (a) Kummer, D. A.; Brenneman, J. B.; Martin, S. F. Org. Lett. 2005, 7, 4621-4623; (b) Kummer, D. A.; Brenneman, J. B.; Martin, S. F. Tetrahedron 2006, 62, 11437-11449; for (-)-dihydroxanthatin, see: (c) Evans, M. A.; Morken, J. P. Org. Lett. 2005, 7, 3371-3373; for (-)-xanthatin, see: (d) Yokoe, H.; Yoshida, M.; Shishido, K. Tetrahedron Lett. 2008, 49, 3504-3506; for a review, see: (e) Shishido, K. Heterocycles 2009, 78, 873-889.

9. For total syntheses of (+)-sundiversifolide, see: (a) Yokoe, H.; Sasaki, H.; Yoshimura, T.; Shindo, M.; Yoshida, M.; Shishido, K. Org. Lett. 2007, 9, 969-971; (b) Ohtsuki, K.; Matsuo, K.; Yoshikawa, T.; Moriya, C.; Tomita-Yokotani, K.; Shishido, K.; Shindo, M. Org. Lett. 2008, 10, 1247-1250; ( \pm )-sundiversifolide, see: (c) Hashimoto, T.; Tashiro, T.; Sasaki, M.; Takikawa, H. Biosci. Biotechnol. Biochem. 2007, 71, 2046-2051; (-)-diversifolide, see: (d) Matsuo, K.; Yokoe, H.; Shishido, K.; Shindo, M. Tetrahedron Lett. 2008, 49, 4279-4281.

10. For a review, see: Molander, G. A. Acc. Chem. Res. 1998, 31, 603-609. 
11. Evans, D. A.; Ennis, M. D.; Mathre, D. J. J. Am. Chem. Soc. 1982, 104, 1737-1739.

12. Sharpless, K. B.; Amberg, W.; Bennani, Y. L.; Crispino, G. A.; Hartung, J.; Jeong, K-S.; Kwong, H-L.; Morikawa, K.; Wang, Z-M.; Zhang, X-L. J. Org. Chem. 1992, 57, 2768-2771.

13. For cyclization of iodo esters with organolithiums, see: (a) Cooke, Jr., M. P.; Houpis, I. N. Tetrahedron Lett. 1985, 26, 4987-4990. (b) Saito, T.; Takeuchi, T.; Matsuhashi, M.; Nakata, T. Heterocycles, 2007, 72, 151-156.

14. The conformational analysis was performed with MMFF force field (CONFLEX v. 6).

15. Higashibayashi, S.; Shinko, K.; Ishizu, T.; Hashimoto, K.; Shirahama, H.; Nakata, M. Synlett 2000, 1306-1308.

16. Without use of $\mathrm{CH}_{2} \mathrm{Cl}_{2}$ as the co-solvent, the diol was mainly generated. See ref. 15 .

17. The keto group on $\mathbf{3 6}$ was inert to olefinations, such as the Wittig or the Peterson reactions, probably due to the steric hindrance of the TBS and TBDPS groups.

18. Garner, P.; Ramakanth, S. J. Org. Chem. 1987, 52, 2629-2631.

19. Kido, F.; Tsutsumi, K.; Maruta, R.; Yoshikoshi, A. J. Am. Chem. Soc. 1979, 101, 6420-6424.

20. Finkielsztein, L. M.; Aguirre, J. M.; Lantano, B.; Alesso, E. N.; Moltrasio Iglesias, G. Y. Synth. Commun. 2004, 34, 895-901.

21. Bates, R. W.; Fernandez-Megia, E.; Ley, S. V.; Ruck-Braun, K.; Tilbrook, D. M. G. J. Chem. Soc., Perkin Trans. 1 1999, 1917-1925.

22. Suzuki, H.; Fuchita, T.; Iwasa, A.; Mishina, T. Synthesis 1978, 905-908.

23. Behan, J. M.; Johnstone, R. A. W.; Wright, M. J. J. Chem. Soc. Perkin Trans. 1 1975, 1216-1217.

24. Higuchi, Y.; Shimoma, F.; Ando, M. J. Nat. Prod. 2003, 66, 810-817.

25. Garber, S. B.; Kingsbury, J. S.; Gray, B. L.; Hoveyda, A. H. J. Am. Chem. Soc. 2000, 122, 8168-8179.

26. Shishido successfully carried out the Mitsunobu reaction at C- 8 by using a less sterically hindered substrate. See ref. $8 \mathrm{~d}$.

27. Dahlen, A.; Hilmersson, G. Chem. Eur. J. 2003, 9, 1123-1128.

28. The stereochemistry was speculated based on the Shishido's stereochemical result in the reaction of diphenyl diselenide and lithium enolate of $\mathbf{6 0}$. See ref. $8 \mathrm{~d}$.

29. (a) Marco, J. A.; Sanz-Cervera, J. F.; Corral, J.; Carda, M.; Jakupovic J., Phytochemistry 1993, 34, 1569-1576. (b) Pinel, B.; Audob, G.; Mallet, S.; Lavault, M.; De La Poype, F.; Séraphin, D; Richommea, P., J. Chromatogr. A 2007 1151, 14-19.

30. Nacro, K.; Baltas, M.; Gorrichon, L. Tetrahedron 1999, 55, 14013-14030. 

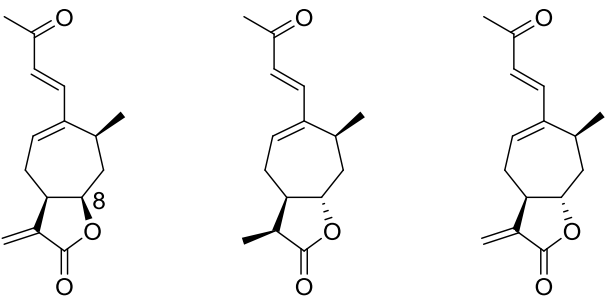

(+)-8-epi-xanthatin (1) (-)-dihydroxanthatin (2)

(-)-xanthatin (3)
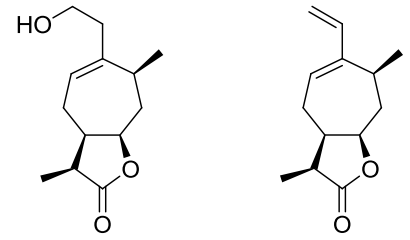

(+)-sundiversifolide (4)

key intermediate (5)

Figure 1. Xanthanolide natural products. 


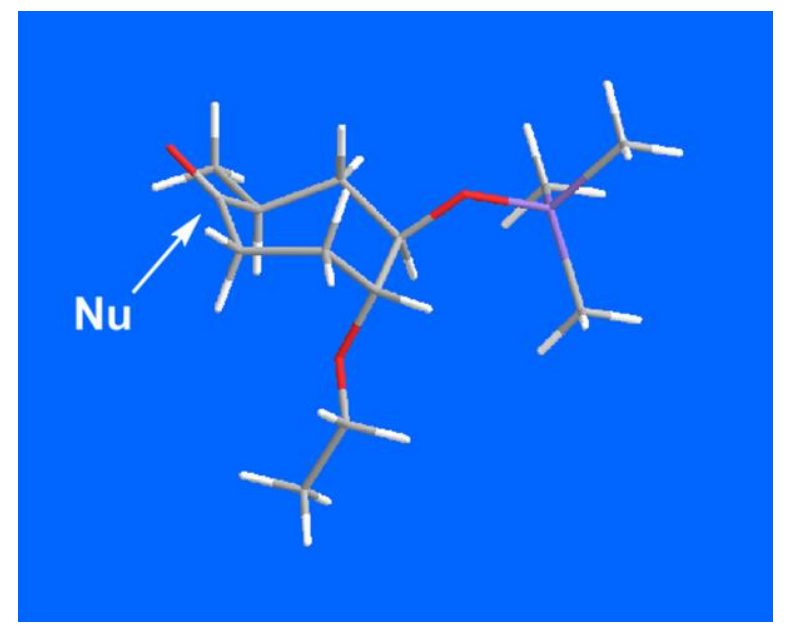

Figure 2. Calculated conformation of $\mathbf{2 0}$ (TBDPS group was replaced by TMS for simplification) 


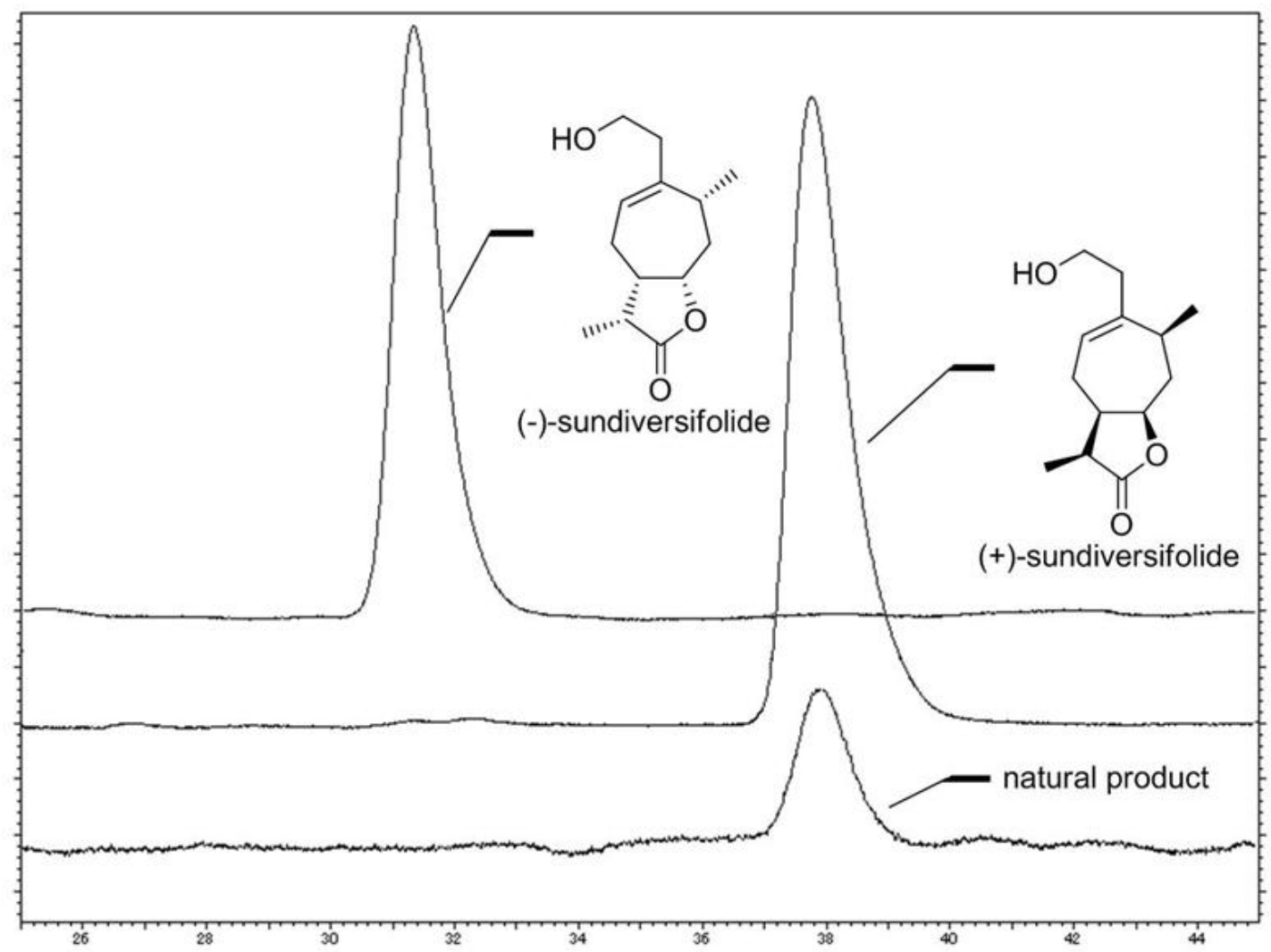

Figure 3. HPLC analysis of natural and unnatural sundiversifolide using a chiral column (Daicel Chiralpak IA, detector: UV $207 \mathrm{~nm}$, hexane/isopropanol 93:7, flow $=1.0 \mathrm{ml} / \mathrm{min}$; (-)-sundiversifolide $t_{\mathrm{r}}=31 \mathrm{~min} ;(+)$-sundiversifolide $t_{\mathrm{r}}=38 \mathrm{~min}, 30^{\circ} \mathrm{C}$ ) 

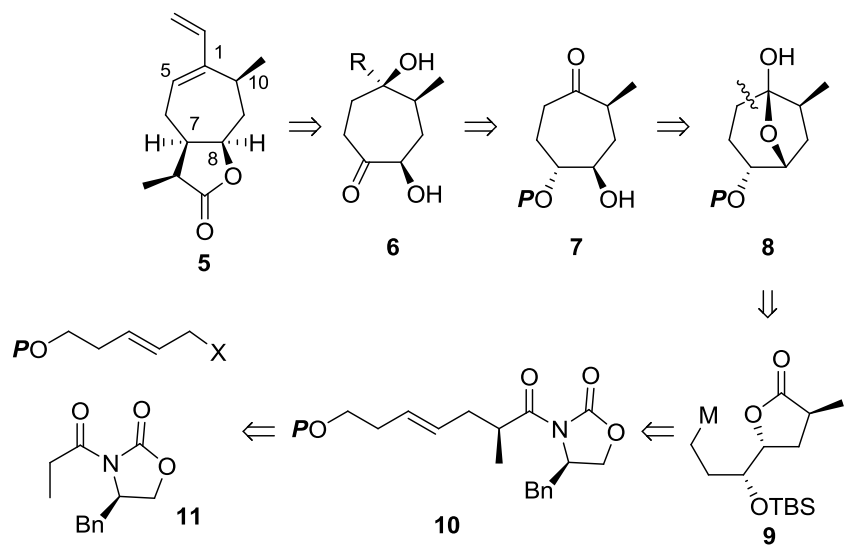

Scheme 1. Retro synthesis of the key intermediate for the xanthanolides. 

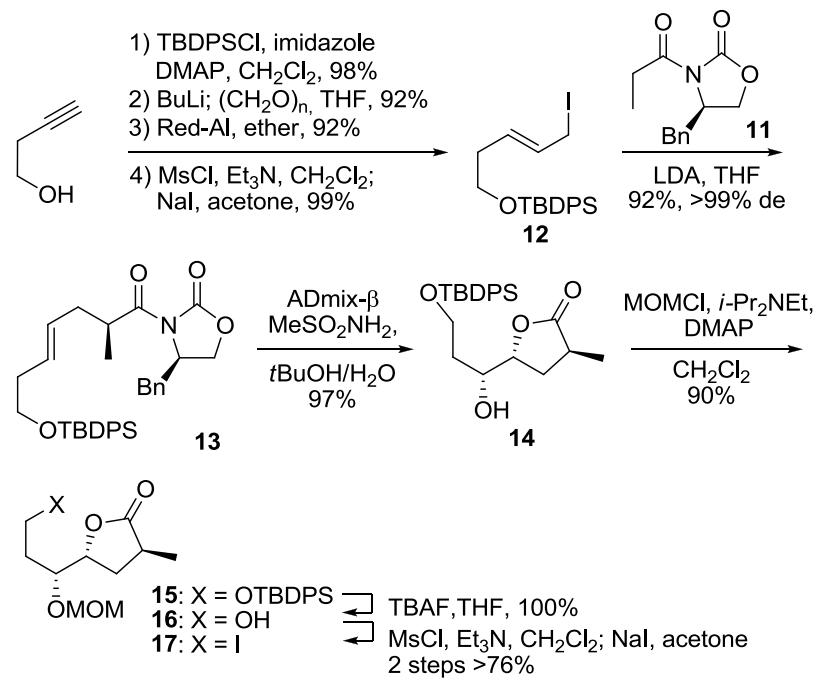

Scheme 2. Asymmetric synthesis of the $\gamma$-lactone 17 . 


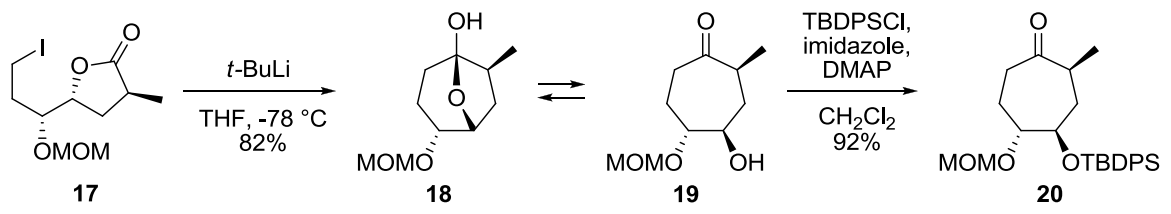

Scheme 3. Intramolecular acylation of the alkyllithium to give the cycloheptanone. 


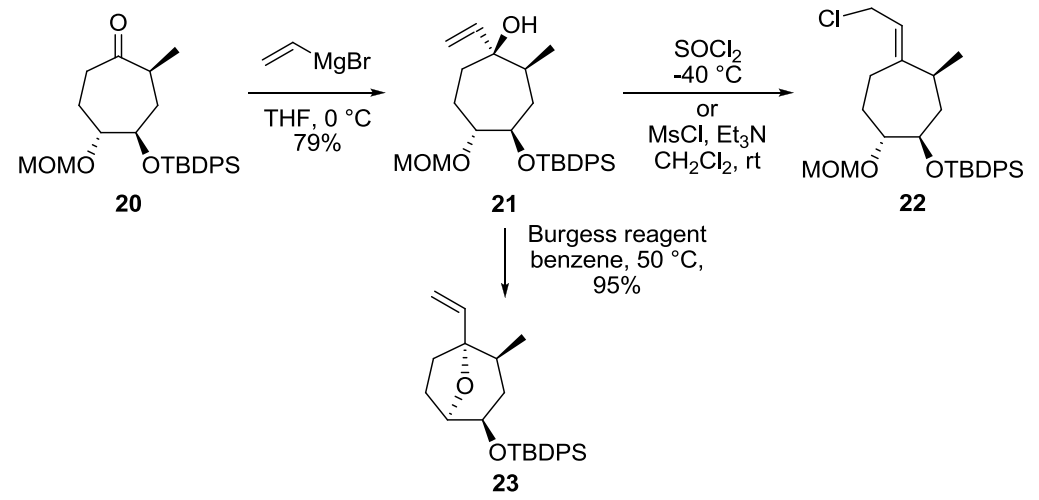

Scheme 4.

32 

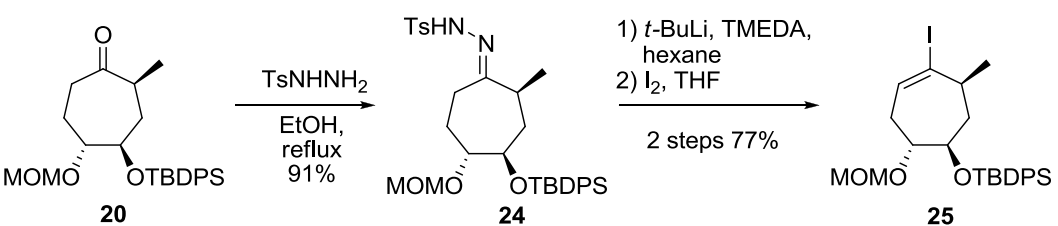

25

$$
\begin{gathered}
\mathrm{Ph}_{3} \mathrm{P}, \mathrm{SnBu}_{3} \mathrm{Pd}_{2}(\mathrm{dba})_{3}, \\
\mathrm{THF} \\
89 \%
\end{gathered}
$$

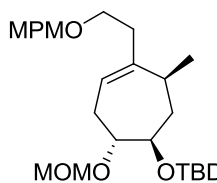

28

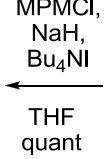

MOMO OTBDPS

27

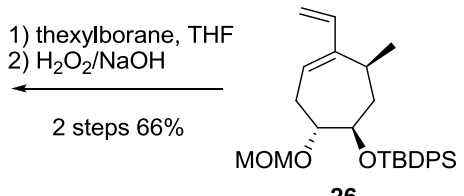

26
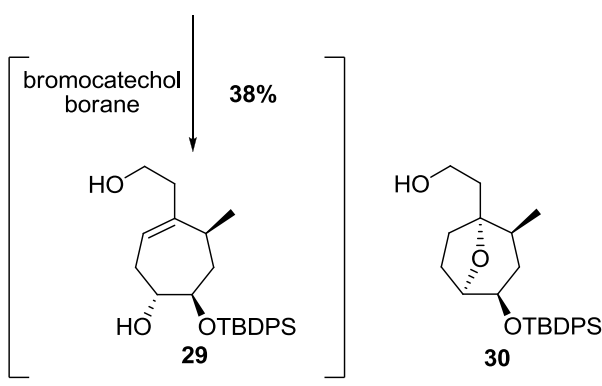

Scheme 5. 


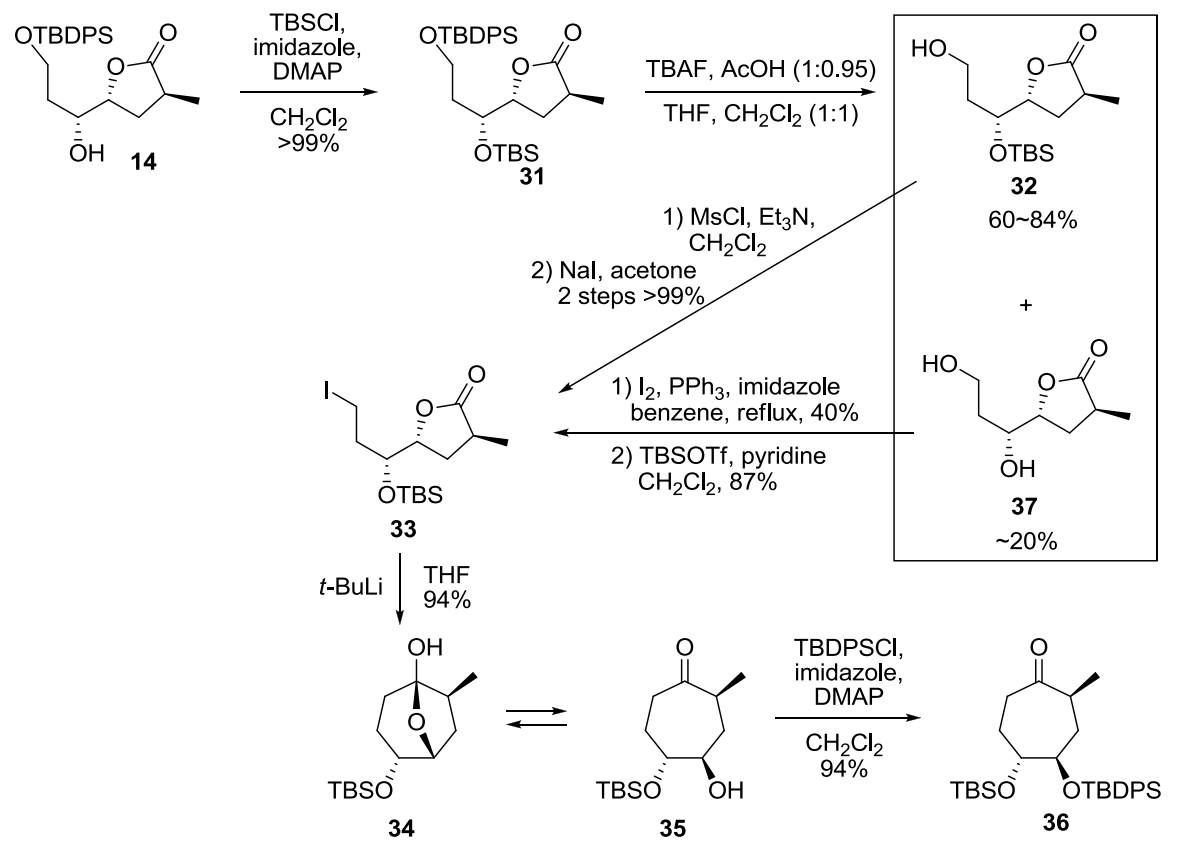

Scheme 6. 


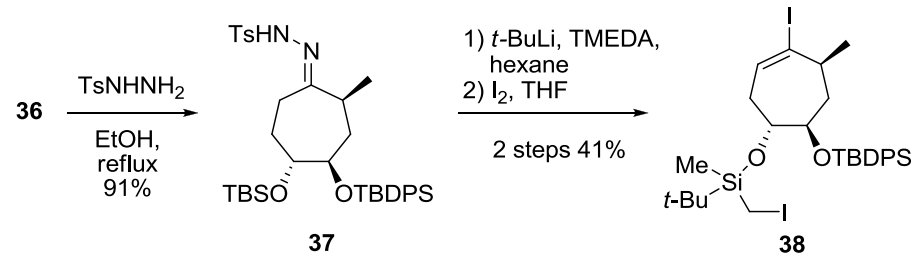

Scheme 7. 

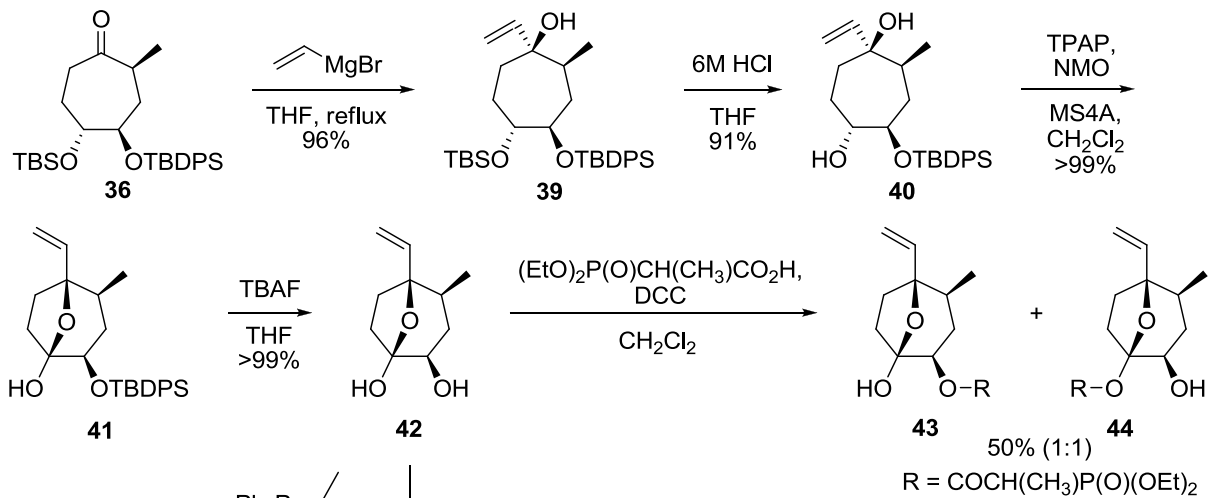

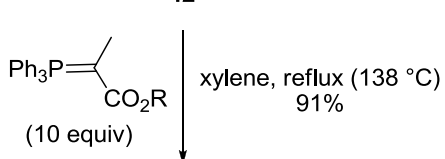

$\mathrm{R}=\mathrm{COCH}\left(\mathrm{CH}_{3}\right) \mathrm{P}(\mathrm{O})(\mathrm{OEt})_{2}$

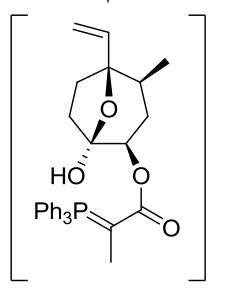

45
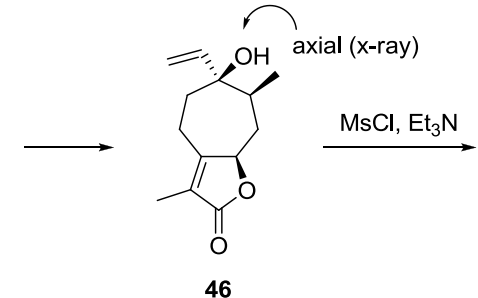

$\mathrm{R}=\mathrm{Et}:$ 91\% (10 h)

$\mathrm{CH}_{2} \mathrm{CF}_{3}: 92 \%(4 \mathrm{~h})$

$\mathrm{Ph}: 74 \%(2.5 \mathrm{~h})$

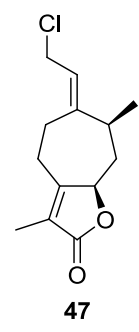

Scheme 8. 

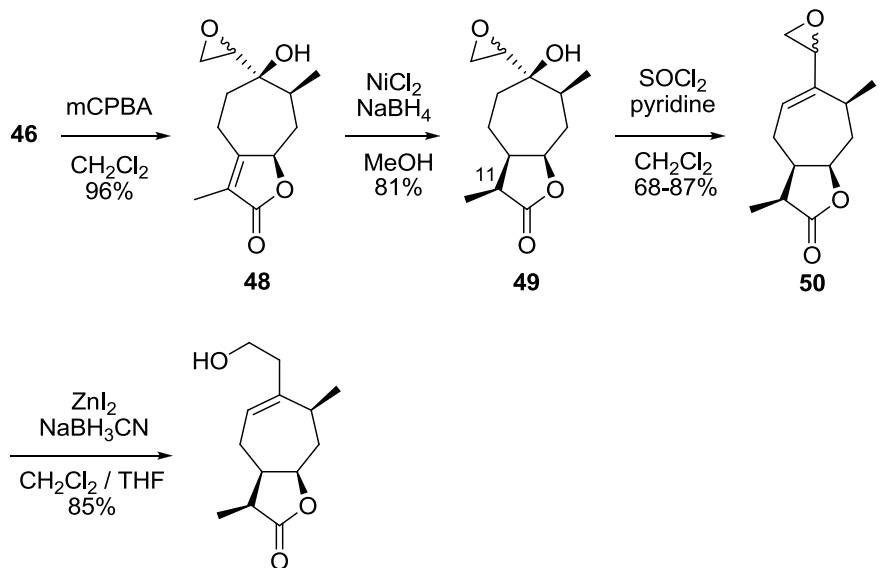

sundiversifolide (4)

Scheme 9. Synthesis of sundiversifolide (4) 


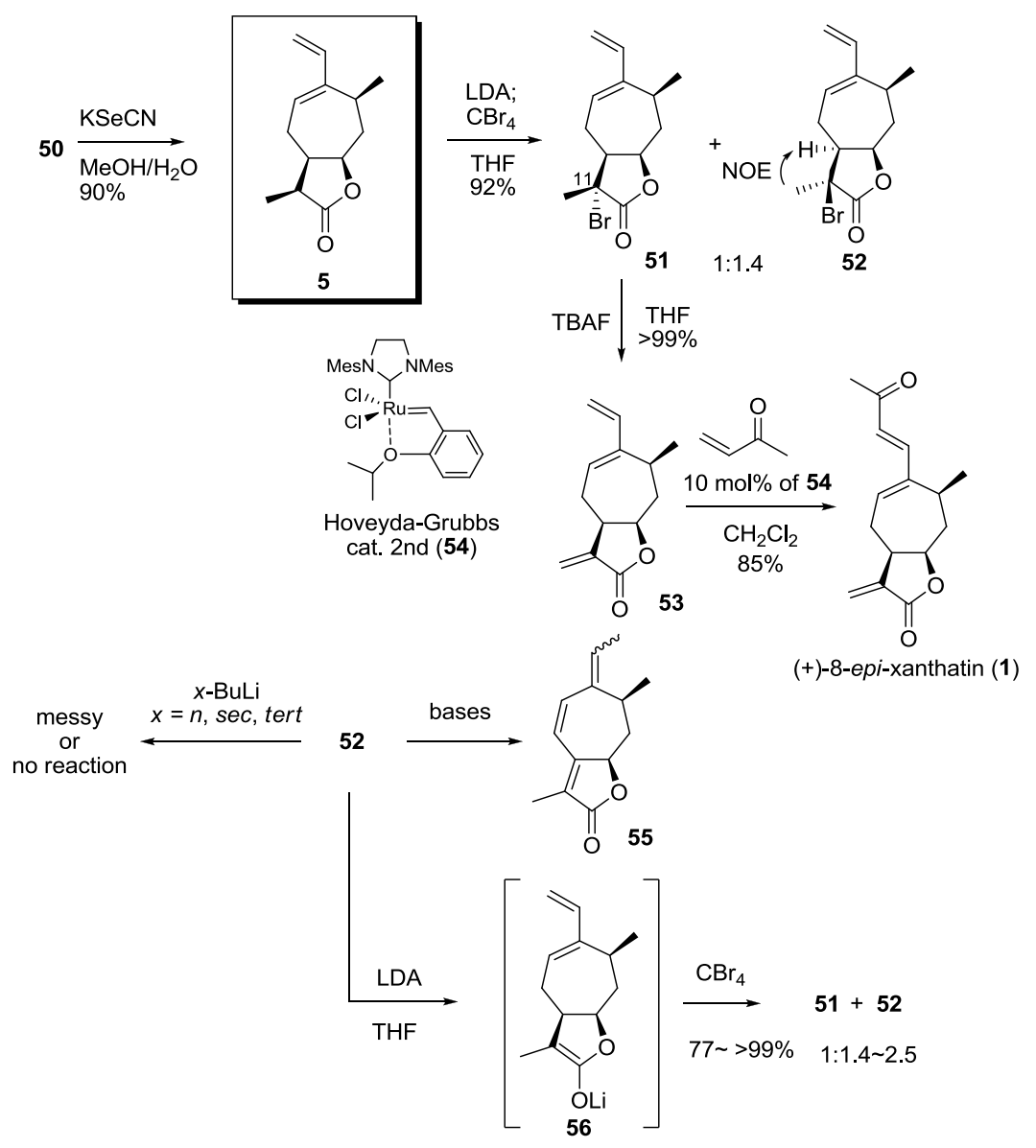

Scheme 10. Synthesis of (+)-8-epi-xanthatin (1) 

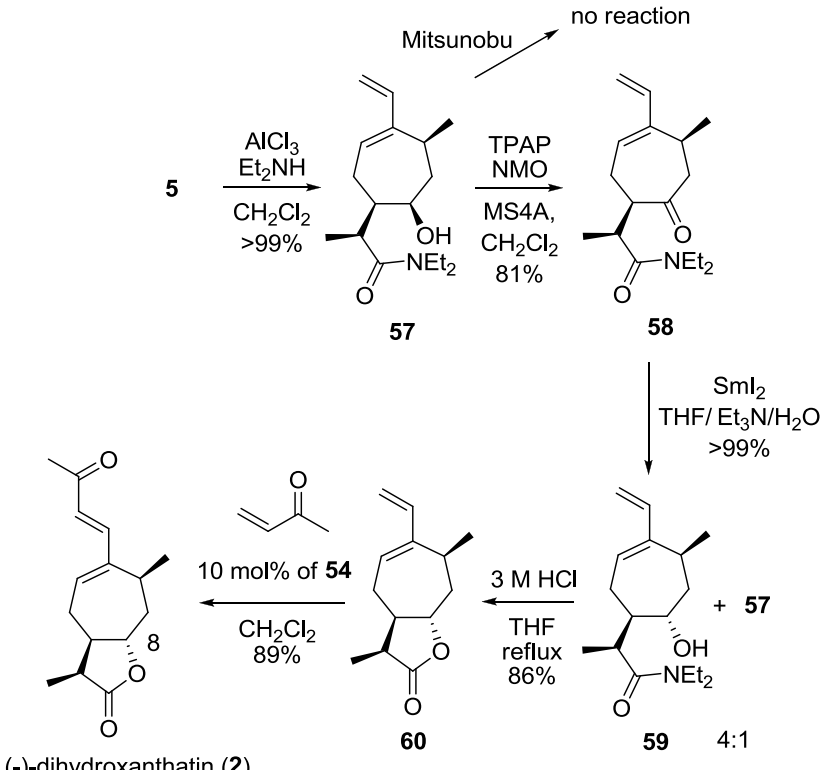

Scheme 11. Synthesis of (-)-dihydroxanthatin (2) 

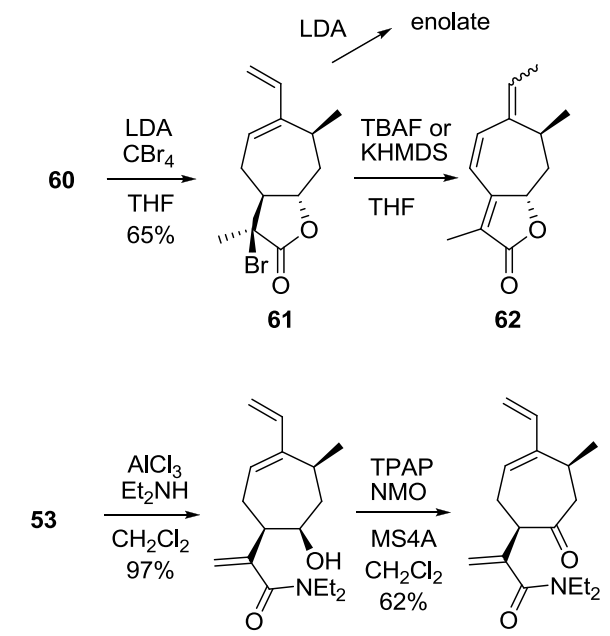

63

64

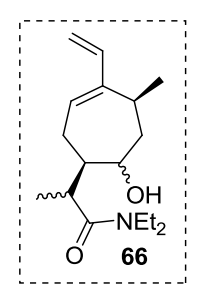

$\downarrow \begin{gathered}\text { DIBAL } \\ \text { THF }\end{gathered}$
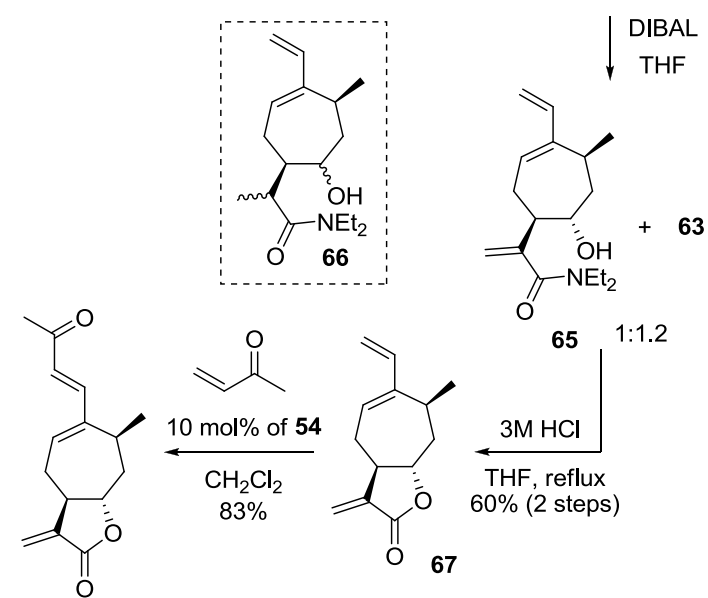

(-)-xanthatin (3)

Scheme 12. Synthesis of (-)-xanthatin (3) 